\title{
The Necessary Competencies for Selecting Academic Leaders in the Sultanate of Oman in Light of the Vision of the Education Strategy 2040
}

\author{
Wajeha Thabit Al Ani \\ Department of Educational \\ Foundations and Administration \\ Sultan Qaboos University \\ wajeha@squ.edu.om
}

\author{
Amal Rashid Al Kiyumi \\ Department of Educational \\ Foundations and Administration \\ Sultan Qaboos University \\ kiyomi@squ.edu.om
}

\author{
Faiza Ahmed Al Shidi \\ Department of Educational \\ Foundations and Administration \\ Sultan Qaboos University \\ s98983@student.squ.edu.om
}

Received: 6/6/2021

Accepted: $25 / 7 / 2021$

\begin{abstract}
:
This study aims to search for the necessary competencies to choose academic leaders in the Sultanate of Oman in light of the vision of the 2040 education strategy. To achieve this aim, a qualitative approach is used, by preparing an interview card that includes five main questions. The sample of the interview consists of nine individuals who occupy leadership positions at the university and whose work is related to the educational field. The sample consists of (the dean of the faculty and his assistants, a sample of department heads, the dean of admission and registration, directors of centres, and the head of the Quality and Accreditation Unit). The data collection period took about one month. The qualitative method is used to analyse the responses of the corresponding sample using the coding system NVivo according to the study fields.

The results of the study show that one of the most important competencies mentioned in the responses is the following competencies: personal competencies, professional competencies, communicational competencies, planning competencies, adequacy of practices, and technological competencies, in addition to the importance of academic leaders possessing the cognitive ability in two main dimensions (academic specialization and professional specialization). Furthermore, there is the importance of having a cultural horizon that helps them deal with various groups of society. As for the factors that influence the academic leader's success and make him distinguished, these are his ability to work with others, to take responsibility, to have the drive for accomplishments, to have the ability to negotiate and conclude deals, and to have the ability to deal with crises or risks. Based on the results of the study, several recommendations and proposals are developed.
\end{abstract}

Keywords: Academic Competencies, Academic Leaders, Higher Education. 


\section{الكفايات اللازمة لاختيار القيادات الأكاديمية بسلطنة عُمان في ضوع التهئ روئية استراتيجية التعليم 2040}

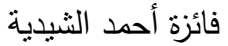 \\ قسم الأصول والإدارة التربوية \\ جامعة السلطان قابوس
}

s98983@student.squ.edu.om

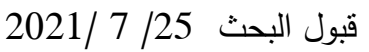

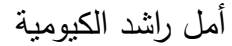

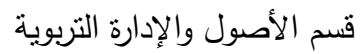 \\ جامعة السلطان قابوس
}

kiyomi@squ.edu.om

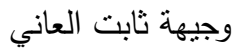

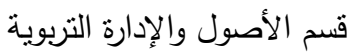 \\ جامعة السلطان قابوس \\ wajeha@squ.edu.om
}

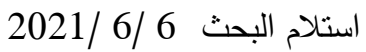

(الملخص:

تهدف هذه الدراسة إلى البحث عن الكفايات اللازمة لاختيار القيادات الأكاديمية بسلطنة عُمان في ضوء رؤية استراتيجية التعليم 2040.

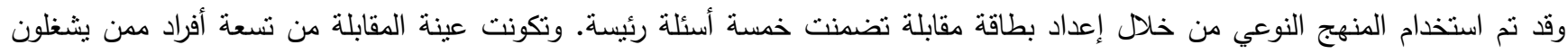
مناصب قيادية في الجامعة ويرتبط عملهم بالمجال الأكاديمي، وتمثلت عينة الدراسة في: (عميد الكلية ومساعدوه، وعينة من رؤساء الأقسام، وعميد القبول والنسجيل، ومديرو المراكز ورئيس وحدة الجودة والاعتماد). واستغرقت مدة جمع البيانات حوالي شهر ، كما تم استخدام المنهج النوعي في تحليل استجابات عينة المقابلة باستخدام نظام التزميز باستخدام برنامج (NVivo) وفقا لدحاور الدراسة.

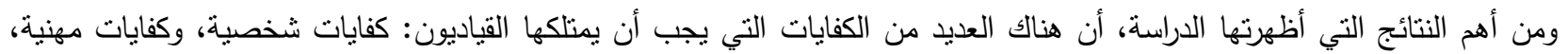
وكفايات التواصل، وكفايات التخطيط، وكفاية التأمل في الممارسات، وكفايات تكنولوجية، إضافة إلى أهمية امتلاك القادة الأكاديميين القدرة

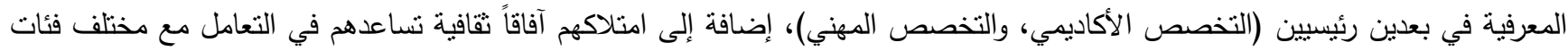
المجتمع. أما بالنسبة إلى العوامل التي تؤثثر في نجاح القائد الأكاديمي وتجعله متميزا فقد تتمثل بقدرته في العمل مع الآخرين، وتحمل المسؤولية،

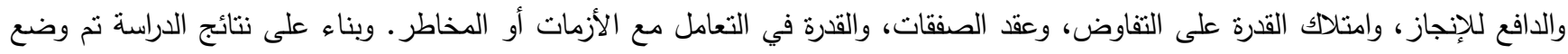
العديد من التوصيات والمقترحات. الكلمات المفتاحية: كفايات أكاديمية، القادة الأكاديميون، تعليم عالي.

كل من (Jamal Al-Din, Al-Suwaidi \& Hassanein) القادة الأكْفاء لا يظهرون فجأة أو عرضيّا، وأن نتافر القيادات

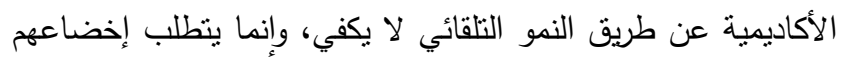

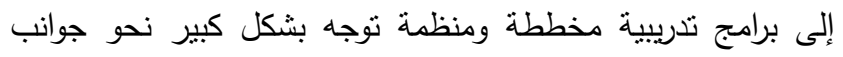

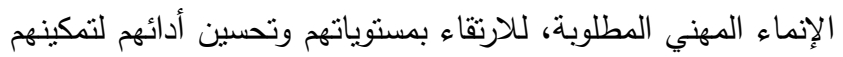
من أداء دورهم في قيادة وحداتهم الإدارية بالثكل الأمثل.

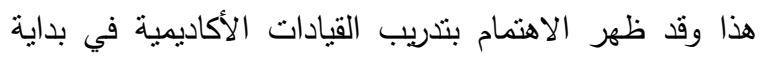
الألفية الثالثة خاصة بعد ظهور تكنولوجيا المعلومات وظهور التقنيات الحديثة وأهمية نوظيفها في العمل الإداري، مما تزايد في الاهنمام

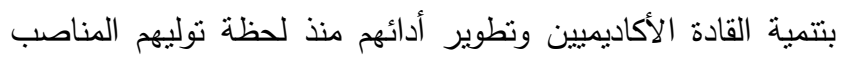
الإدارية، فالمهام الإدارية من تخطيط وتنظيم وتوجيه ورقابة ومتابعة

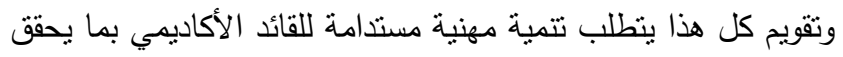

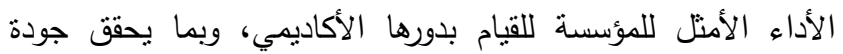

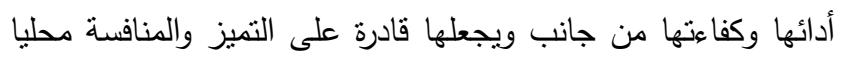
وعالميا من جانب آخر (10).

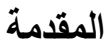

تتخذ الجامعة كمؤسسة أكاديمية الدور القيادي في تحقيق مسيرة المجتمعات نحو التطور وفقا لمنطلبات الخطط التتموية فيها، لذا فإن

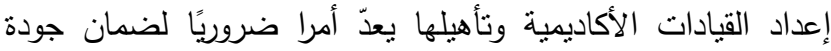

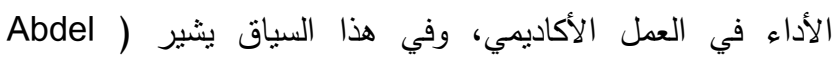
(Rahim) إلى أهمية التدريب قبل شغل الوظيفة وبعد شغلها، كونه

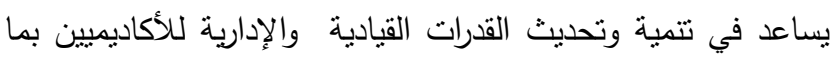
يمكنهم من إحداث التغيير الدستهدف وتطوير الخبرات الذاتية في مجال إدارة المؤسسة الأكاديمية، حيث إن هنالك العديد من المهارات

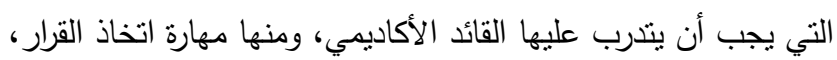

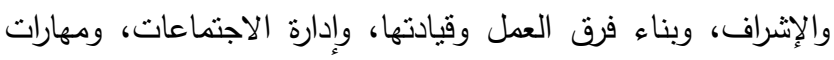
تقديم الاستشارات، والتعامل مع التكنولوجيا، وإدارة الوقت، وإدارة الأزمات، وغيرها من المهارات القيادية. ويؤكد (Ragheb) (17) أن نطوير أداء القادة الأكاديميين هو أنونة

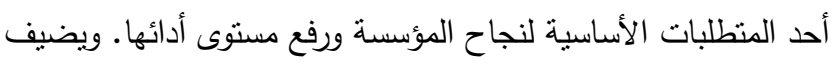


كليات جامعة الأنبار، في التوجه استباقيًا لإدارة الأزمات التي نواجه

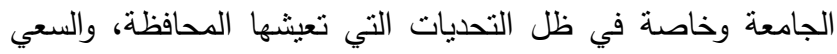
لتحجيم الفجوة بين مراحل استباق الأزمة وبين اتخاذ الإجراءات القيادية الآنية واللاحقة لمواجهة هذه الأزمة، وقد تكونت عينة البحث من (140) شخصا من رؤساء الأقسام والهيئة التنريسية الذين يشغلون مسنويات تتظيمية مختلفة في كليات الجامعة، واتبعت الدراسة المنهج الوصفي الارتباطي. وتم استخدام الاسنبانة وبطاقة المقابلة الثخصية

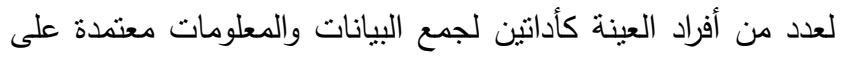

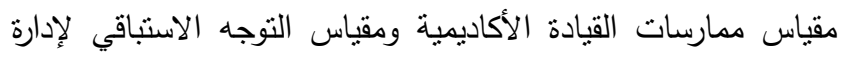

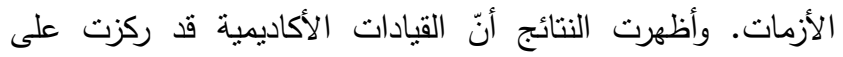

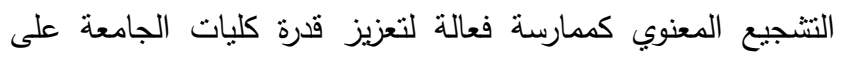

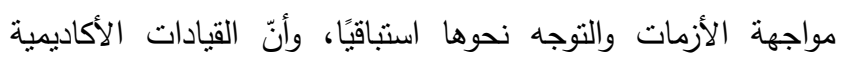

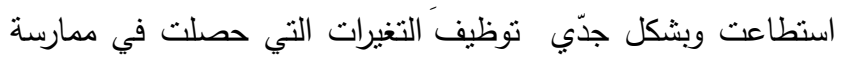
تمكين المرؤوسين نحو العمل في إحداث المزيد من التغيرات الإيجابية في مجال تعزيز القدرة نحو التوجه الاستباقي لإدارة الأزمات.

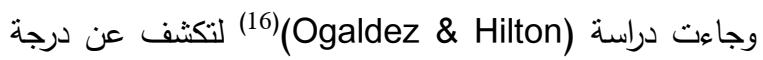
توقعات أعضاء هيئة الندريس للقيادات الإدارية في سلوك رؤساء الأقسام في جامعة بليز (Belize)، وقد نم استخدام مقياس الصفات السلوكية للقيادة الأكاديمية Description Leader Behavior) Ohio (المُعدّ من قبل جامعة أوهايو الحكومية (Questionnaire (State University

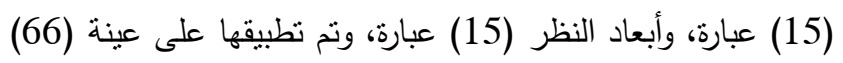

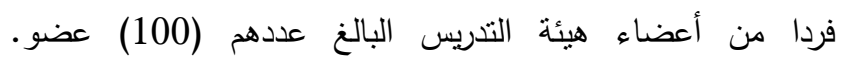

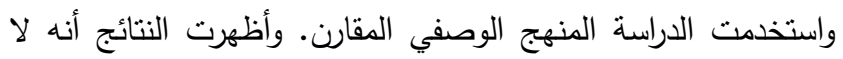

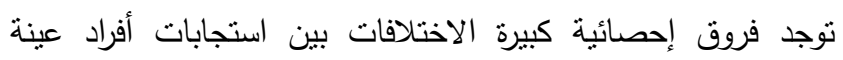

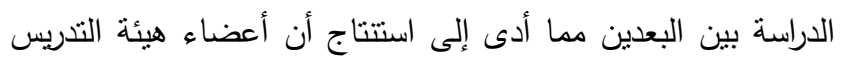

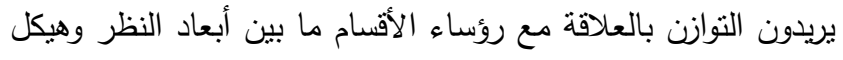

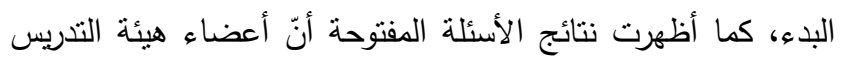

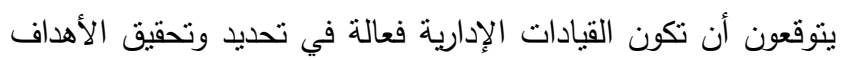
الإدارية، وأن نكون العلاقة مبنية على الثنة والاحترام المتبادلين،

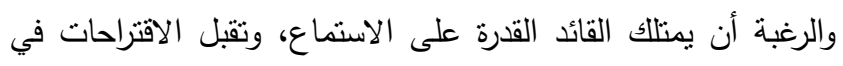
حلّ المشكلات، وتعزيز روح العمل الجماعي والتعاون.

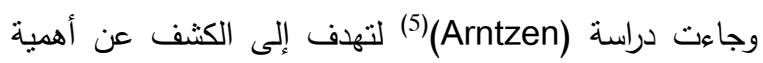

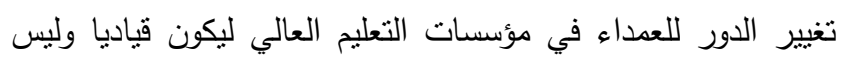

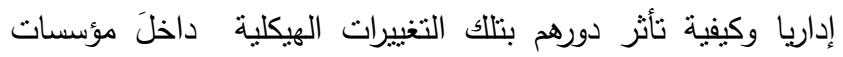

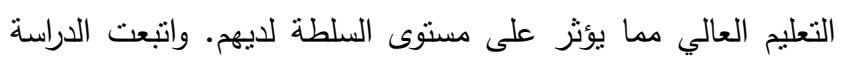

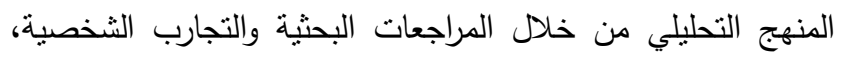

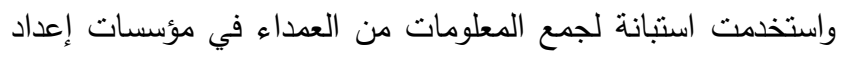

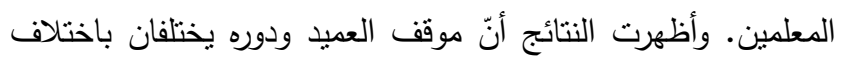
النموذج النتظيمي، ومع ذللك، فإنّ جميع العداء يمارسون سلطتهم

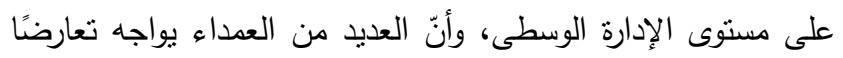

كما يؤكد (Yaghi) (22) على أهمية برامج الإنماء المهني للقادة الأكاديميين كونها تعمل بشكل كبير على رفع مسنوى الكفاية الإنتاجية

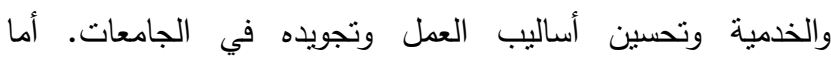
(14)(Kaddouri)

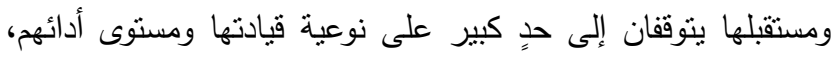

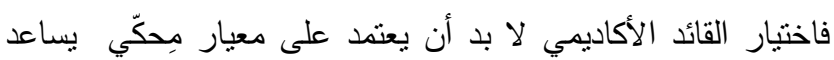

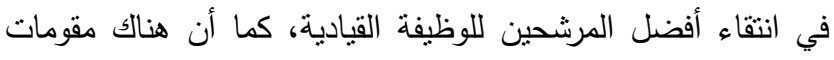

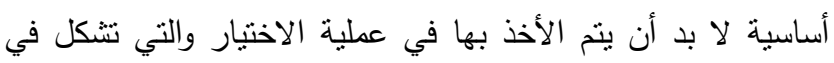

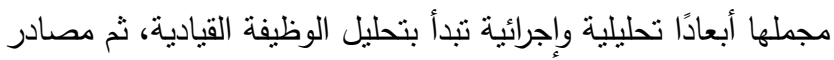
الاختيار ، ثم إجراء الاختيار . ومن الخصائص الأخرى التي يتميز بها القائد الأكاديمي هي التياري

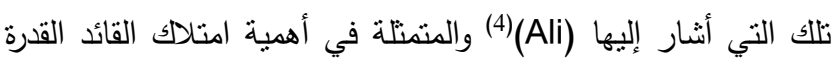

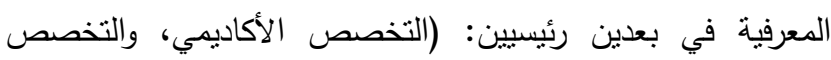

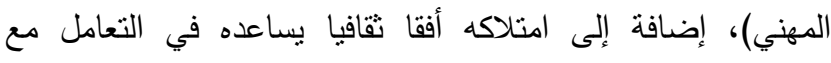

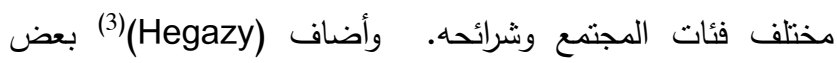
الخصائص التي تؤثز في نجاح القائد الأكاديمي وتجعله متميزا، والتي تتمثل في قدرته في العمل مع الآخرين، وتحمل المسؤولية، والدافع للإنجاز، والقدرة على التفاوض وعقد الصفقات، والاستعداد للتعامل مع المخاطر . الدراسات السابقة

من خلال مراجعة الدراسات السابقة المتعلقة بالقيادات

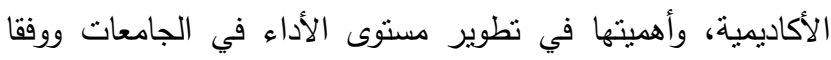
لأهداف الدراسة؛ فيما يلي عرض لبعض في هذئ هذه الدراسات:

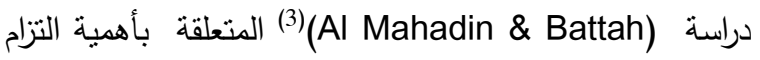
القيادات الأكاديمية في الجامعات الأردنية الرسمية بالأخلاقيات المهنية

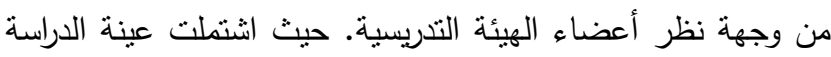

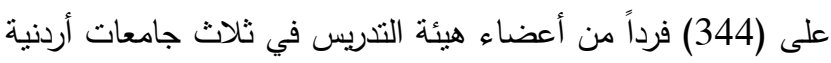
والبالغ عددهم (2320) عضواً، ونم انباع المنهج الوصفي والاستبانة التي طُورت كأداة للكثف عن درجة التخدام التزام القيادات الأكاديمية

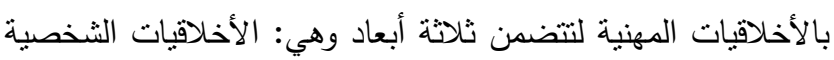
(26) عبارة، والأخلاقيات الإدارية (25) عبارة، والأخلاقيات الإنسانية

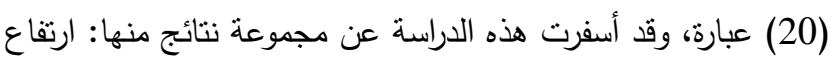

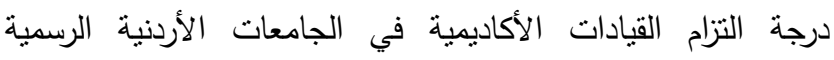

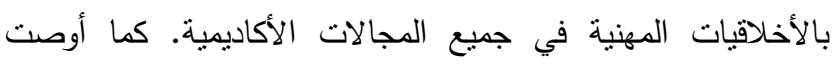

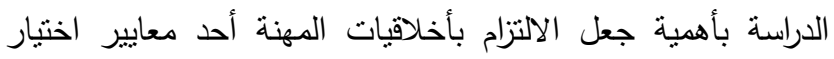

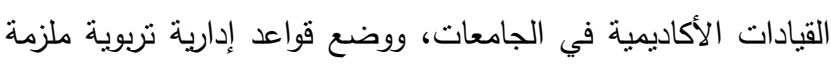

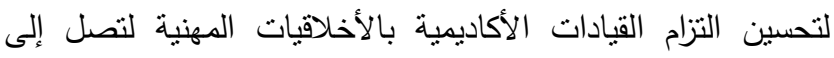
أعلى مستوى لها.

وهدفت دراسة (Salah El-Din \& Attia) (18) الكشف عن هن درجة مساهمة الممارسات المتبعة من قبل القيادات الأكاديمية في 
وإلى معرفة أفضل السبل التي قد تساعد القيادات الإدارية الأكاديمية بجامعة الدمام لزيادة ممارستهم للقيادة التحويلية، من خلال تطبيق الدراسة على عينة عشوائية مؤلفة من (209) أعضاء من (677) عضوا من أعضاء هيئة التدريس في كليات التربية والعلوم والآداب والدراسات التطبيقية وخدمة المجتمع بجامعة الدمام، كما استخذمت لهات الدراسة المنهج الوصفي التحليلي، وصمت استبانة كأداة مؤلفة من

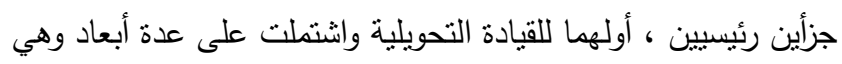
: الجاذبية ، التأثير المثالي، والحفز الإلهامي، والاستثارة الفكرية،

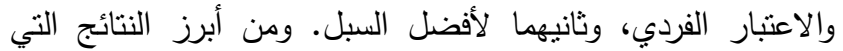

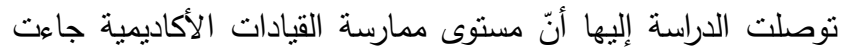
بدرجة "متوسطة"، وفي محاور الاستتارة الفكرية والحفز الإلهامي

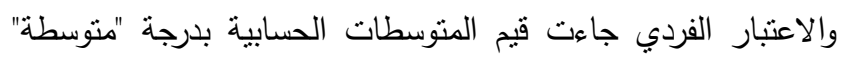
و"أقل من المتوسطة"، بينما سجل مستوى قيم التأثير المثالي درجة "ضعيفة وفوق متوسطة". وجاءت دراسة (Hassan)(11) لتكثف عن وند أهمية تتمية مهارات القيادة الإستراتيجية للقيادات الأكاديمية بالجامعات المصرية من خلاد معرفة القيادة الإستراتيجية ومبادئها وممارساتها وصفات القائد الاستراتيجي، ومعرفة الواقع الحالي للقيادات الأكاديمية بالجامعات

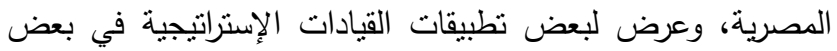
الجامعات الأجنية، والتوصل لبعض الإجراءات المقترحة لتتمية مهارة

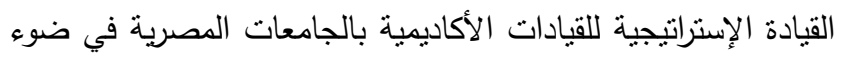
تطبيقاتها ببعض الجامعات الأجنية، مستهدفة عينة من أعضاء هيئة

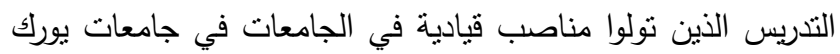

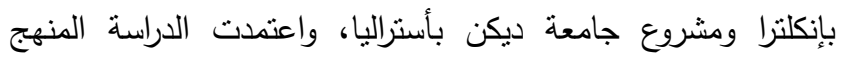

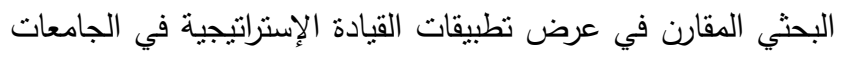
الأجنبية (إنكلنرا وأستراليا) بما ينتاسب والواقع الدصري والإمكانيات المتاحة وتحليل لبعض الوثائق الرسمية والقرارات والدراسات السابقة في

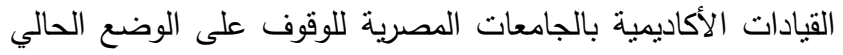
بمصر، وتحديد بعض الإجراءات للاستفادة من نطبيقات القيادة

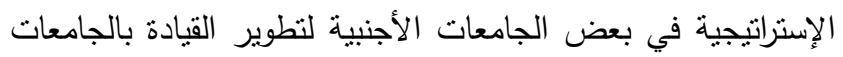

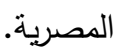
ولأهمية تمكين القيادات الأكاديمية في الجامعات؛ جاءت دراسة (2)(Abdul Hadi \& Hatata) الأكاديمية في جامعة كفر الثيخ، وماهية تمكين القيادات الأكاديمية بالجامعة، والوقوف على واقع تمكين القيادات الأكاديمية بالجامعات المصرية من منظور الوثائق، والوقوف على واقع تمكين القيادات

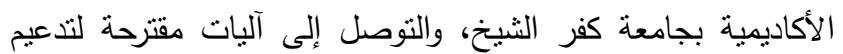
تمكين القيادات الأكاديمية بالجامعة. وصمدت استبانة كأداة للبحث

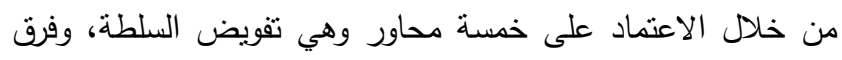
العمل، والتدريب، والاتصال الفعال، وحفز القيادات. وقد طبقت هذه الدراسة على عينة مؤلفة من (95) عضوا من القيادات الأكاديمية
بين كونه مديرًا ينفذ ويدير القرارات والسياسات المؤسسية والحكومية،

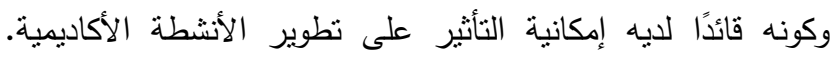

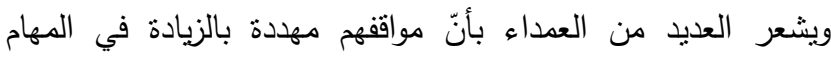
الإدارية، وأنّ الخبرات في التدريس والبحث ليست مهمة بالضرورة للقيام بعمل العداء، وأنّ التغييرات في دور العدداء ربما تعني إضفاء الإداء الطابع المهني على القيادة الأكاديمية. ولأهمية امتلاك الإداريين في الجامعات البحثية لمهارات القيادة الأكاديمية فقد جاءت دراسة (Morris, Joseph \& Laipple) للتعرف على مدى امتلاك الإداريين للمهارات القيادية وممارسة أدوارهم الوظيفية من جانب مستوى الرضا لديهم في جامعات الأبحاث

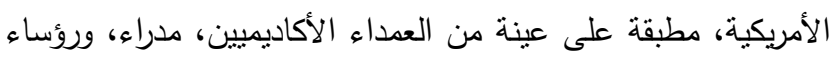

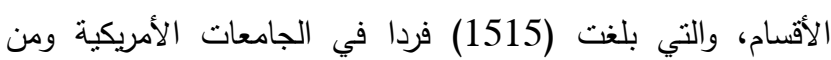

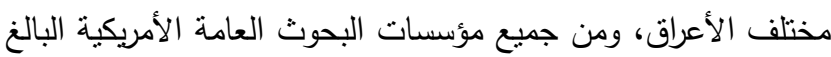
عددها (145) جامعة (جميع الولايات الخمسين)، وقد طبقت الاستبانة كأداة لهذه الدراسة تتضمن (102) عبارة لتطوير أو تحسين المهارات

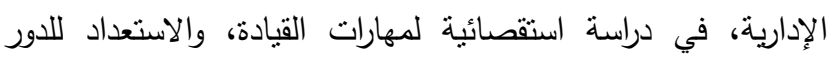

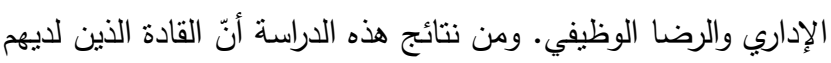

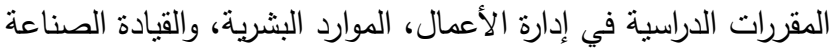

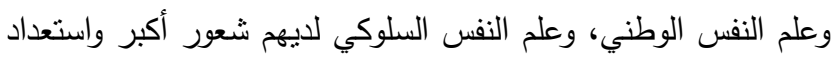

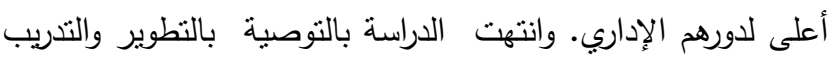

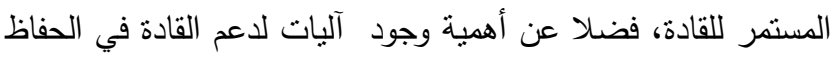
على السلوكيات العامة. أما دراسة (Gonzalez \& Sutton) (8) فقد هدفت إلى الكثف عن إمكانية استفادة الجامعات الأندونيسية من تفعيل القيادة الأكاديمية وذلك بالاستفادة من خبرات الجامعات الأمريكية. واستخدمت الدراسة

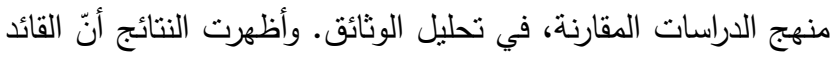

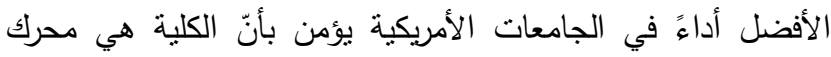

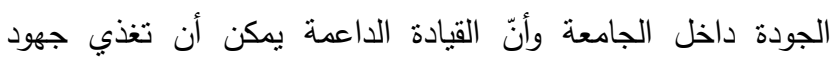

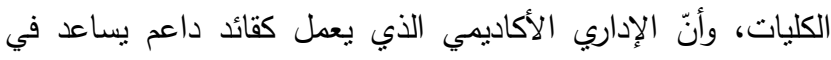
إيجاد البيئة الصحية لإنماء الجوانب الثخصية والمؤسسية والمالية اللازمة لاعم مستويات عالية من الأداء من قبل أعضاء هيئة

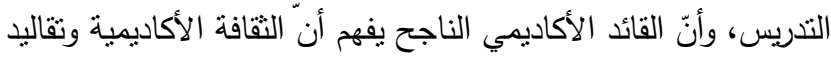

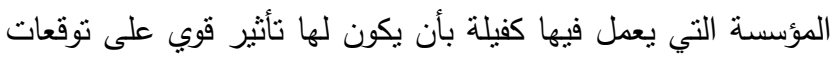

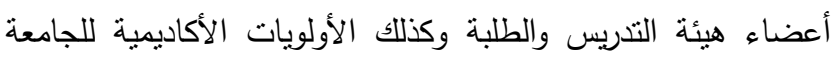

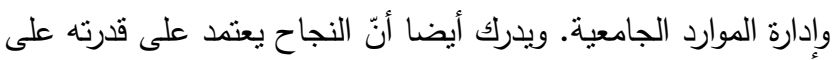

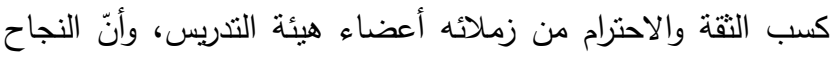

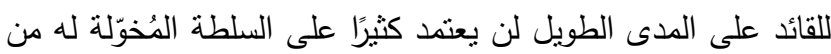

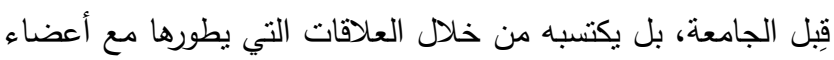
هيئة التدريس والموظفين والطلبة والمشرفين الإداريين. كما هدفت دراسة (Bubshait)(7) إلى الكثف عن درجين ممارسة القيادات الإدارية الأكاديمية بجامعة الدمام للقيادة التحويلية 
الكثف عن كيفية أن يصبح القائد الأكاديمي أكثر فاعلية من خلال التعرف على القيادة الأكاديمية الفاعلة في الجامعات المصنفة عالميًا

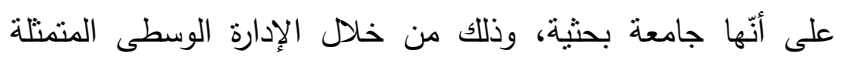
بالعدداء ورؤساء الأقسام حيث إنّ فاعلية القيادة غالبا ما ترتبط بالقيادة الموقفية في الجامعات العالمية وخاصة عند العمل في سياق عالمي.

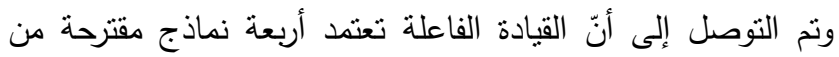
هيرسي وبلانشارد يوتن - فرووم وهي الإخبار والعرض والإنشرالك والتشثيل. ويجب ان تُشتخدم هذه النماذج وفقا لقدرة التابعين ورغبتهم في تتفيذ هذه المهام، كما أنّ القيادة الأكاديمية الفاعلة تحتاج كفاءات

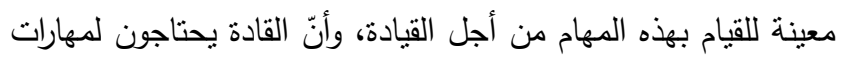

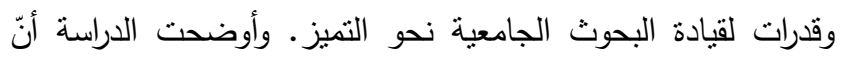

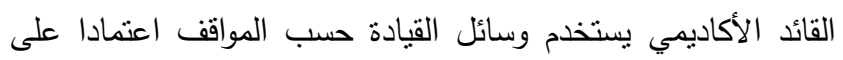
قدرته ومسؤولياته عند تعيينه كعميد أو رئيس قسم في الجامعات

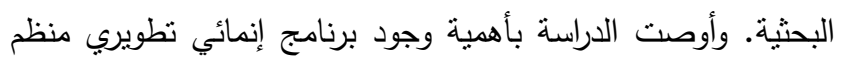
يساعد في ضمان فاعلية القيادة الأكاديمية.

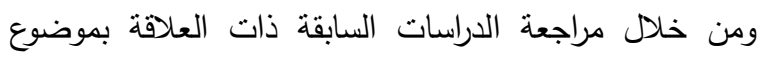
القيادة الأكاديمية تمّ النوصل إلى أنّ الدراسات التي أجريت عن القيادة

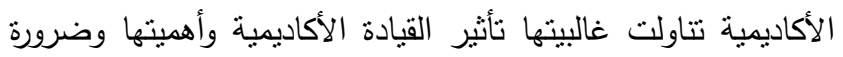
تفعيلها، وأهية امتلاك الإداريين التربوبين لمهارات القيادة الأكاديمية، وأهمية تتمية تلك المهارات، كذلك أهمية تمكين القيادات الأكاديمية.

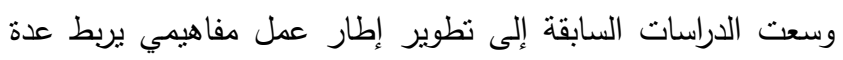

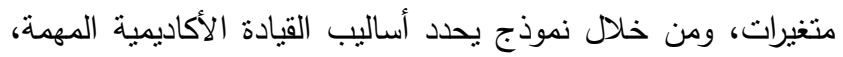

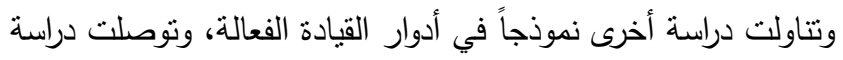
(11)(Hassan)

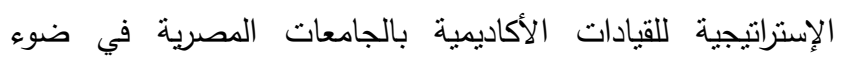

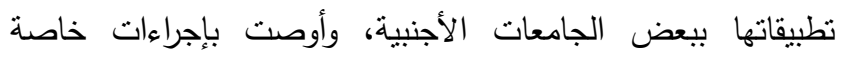
مرتبطة بالتطبيق من خلال تبني مشروع تدريبي لنتمية مهارات القيادة

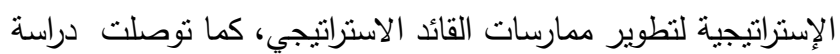
(2) (2) إلى آليات مقترحة لدعم تمكين

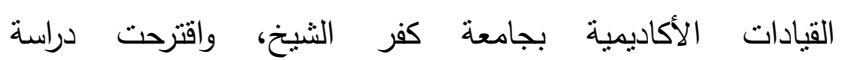

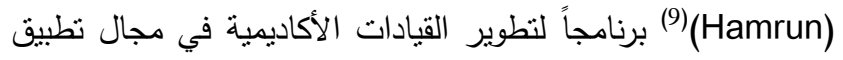

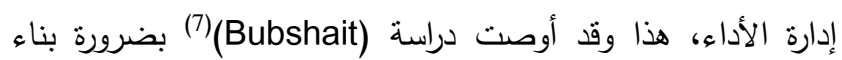
معايير واضحة لاختيار القيادات الأكاديمية بالجامعات.

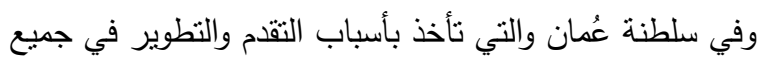
مجالات الحياة ولا سيما ما يتعلق بالتعليم، نأني استراتيجية التعليم 2040 في السلطنة لتتمثل في: "بناء موارد بشرية تمنلك المهارات

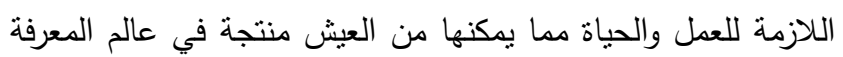
ومؤهلة للتكيف مع متغيرات العصر"، ومن منطلق هذه الروئة تبنت السلطنة مفهوما واسعا لتتمية الموارد البشرية، لهذا اهتمت كافة خطط التتمية الخمسية المتلاحقة بتتمية الموارد البشرية وفق هذا المفهوم الواسع. وحددت الروية المستقلية للاقتصاد العُماني 2020 التوجهات
بكليات جامعة كفر الثيخ؛ معتمدة المنهج الوصفي (دراسة الحالة).

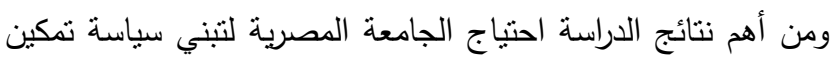

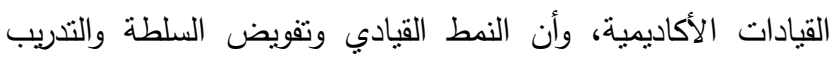
والتحفيز من أهم مقومات تمكين القيادات الأكاديمية. أما حول إدارة الأداء لاى القيادات الأكاديمية بجامعة تبوك فقادية

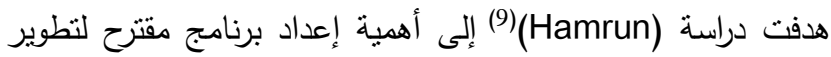

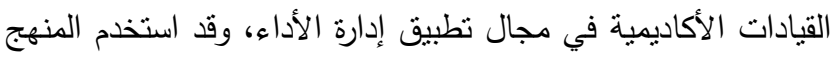
الوصفي. واشتملت عينة الدراسة على (87) فردا من أعضاء هيئة التدريس من مختلف الجنسيات والتخصصات والمستويات الأكاديمية، وتم إعداد استبانة كأداة رئيسة مكونة من (78) عبارة للكثف عن الكن ممارسة القيادات الأكاديمية لأسلوب إدارة الأداء والتي تضمنت ستة أنة

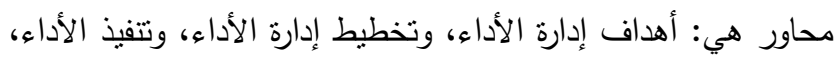

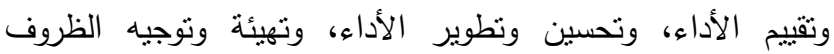

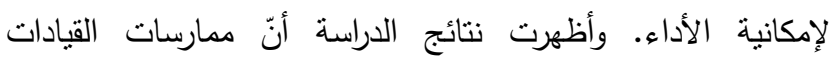

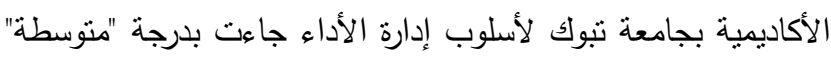

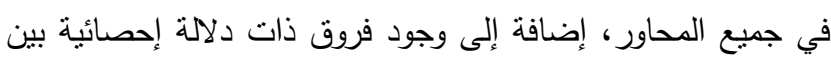

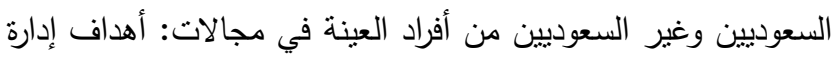
الأداء، وتخطيط إدارة الأداء، وتهيئة ونوجيه الظروف لإمكانية الأداء، وتتفيذ الأداء، وتحسين وتطوير الأداء جميعها لصالح غير السعوديين. وأوصت الدراسة بأن يكون برنامج إدارة الأداء كمدخل لتحسين أداء

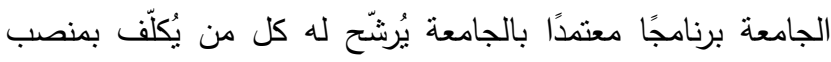

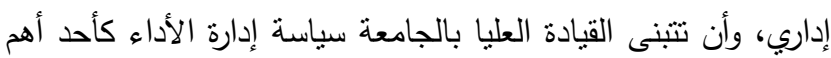
الأساليب الإدارية لنطوير الجامعة.

Siddique, Aslam, Khan \& ) كما جاءت دراسة (21)(Fatima

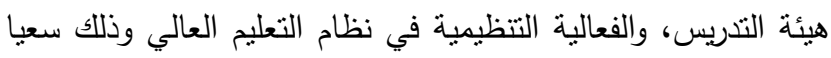
إلى تطوير إطار عمل مفاهيمي يربط هذه المتغيرات (القيادة، والدافع، لفئه

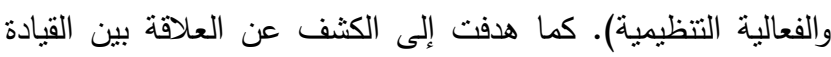

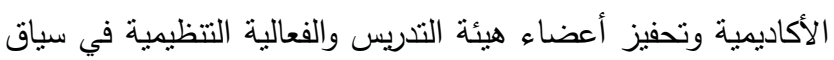

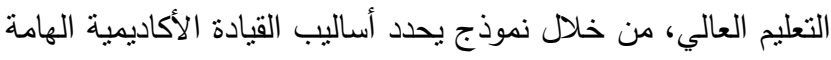
الني يمكن أن تساعد في تحفيز أو إرضاء أعضاء هيئة التشريس من فئن خلال تقديم مكافآت مختلفة. وأظهرت الدراسة أنّ الإطار الدفاهيمي

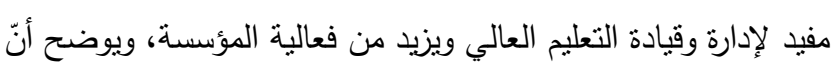
المؤسسة الفعّالة يمكنها خدمة طلابها بشكل أفضل، كما أنّ التطوير لإدير

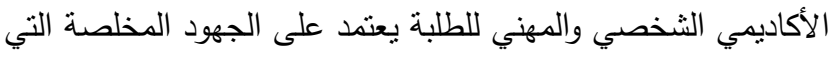
يبذلها أعضاء هيئة النتريس، كما أنّ لإستراتيجيات القيادة الفعالة دوراً فاعلاً في الحفاظ على أعضاء هيئة التدريس المؤهلين تأهيلًا عاليًا.

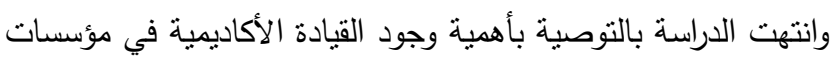
التعليم العالي بأنواعها الثناثة كقيادة بحثية وتعليمية وإدادية وادية. أما حول أهية وجود قيادة أكاديمية فاعلة فقد هدفت دراسة ${ }^{(20)}$ (Shahnandi, Silong, Ismail, abu Samah, Othma) 
1. ما الكفايات اللازمة للقيادات الأكاديمية بكلية التربية بجامعة

السلطان قابوس بسلطنة عُمان في ضوء روية استراتيجية

التعليم 2040 من وجهة نظر عينة الدراسة؟

2. ما المعوقات التي تواجه القيادات الأكاديمية في تمثل هن

الكفايات اللزمة للقيادات الأكاديمية في ممارساتهم بكلية

التربية بجامعة السلطان قابوس؟

3. ما الإجراءات المقترحة لتطوير كفايات القيادات الأكاديمية

بكلية التربية بجامعة السلطان قابوس؟

\section{أهداف الدراسة}

تسعى هذه الدراسة لتحقيق الأهداف التالية:

1. الكثف عن الكفايات اللازمة للقيادات الأكاديمية بكلية التربية

بجامعة السلطان قابوس بسلطنة عُمان في ضوء روية إستراتيجية

التعليم 2040 من وجهة نظر عينة الدراسة.

2. تعرُّف المعوقات التي تواجه القيادات الأكاديمية في تمثل الكفايات اللازمة للقيادات الأكاديمية في ممارساتهم الأكاديمية بكلية التربية

$$
\text { بجامعة السلطان قابوس. }
$$

3. اقتراح برامج لتطوير كفايات القيادات الأكاديمية بكلية التربية بجامعة السلطان قابوس.

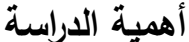

$$
\text { تكمن أهمية الدراسة في: }
$$

- تقديم صورة واضحة للمختصين والقيادات الأكاديمية

$$
\text { بالكفايات اللازمة للقيادة الأكاديمية. }
$$

- - تسليط الضوء على التحديات التي تواجه القيادات الأكاديمية

بكلية التربية بجامعة السلطان قابوس، من أجل العمل على

إيجاد الحلول المناسبة لتذليلها.

- - الاستفادة من البرامج التدربيية المقترحة في الدراسة الحالية

لتطوير القيادات الأكاديمية بمؤسسات التعليم العالي.

\section{حدود الدراسة}

الحدود البشرية: اقتصرت الدارسة على القيادة الأكاديمية بكلية التزبية بجامعة السلطان قابوس والمنمثلة في: (عميد كلية، مساعد

$$
\text { عميد، رئيس قسم، مدير مركز) . }
$$

الحدود المكاتية: كلية التربية بجامعة السلطان قابوس.

الحدود الزمنية: طبقت هذه الدراسة في العام الدراسي الجامعي

$$
\text { . (2020/2019) }
$$

الحدود الموضوعية: سعت هذه الدراسة إلى الكثف عن

الكفايات اللازمة للقيادة الأكاديمية بكلية التربية بجامعة السلطان قابوس بسلطنة عُمان.
المستقبلية للموارد البشرية التي تمثلت في تكوين موارد بشرية ذات قدرات ومهارات تستطيع مواكبة التطور التقني والتكنولوجي، وإدارة المتغيرات التي تحدث فيه بصورة عالية، وكذلك مواجهة الظروف المحلية والعالمية المتغيرة باستمرار. ونتيجة لهذه الجهود جاءت السلطنة على رأس قائمة الدول الأسرع في تتمية مواردها البشرية خلال الأربعين عاما الماضية وفقا لتقرير التتمية البشربة الصادر عن برنامج الأمم المتحدة الإنمائي في (2010م) (6). وبالرغم من ذللك ما زال قطاع التعليم في السلطنة يواجه العديد من التحديات، وذلك كما أثنارت الدراسات والتقارير التي قامت بها الجهات المعنية بالتعليم في السلطنة، مثل تقرير وزارة التربية والتعليم بالتعاون مع البنك الدولي (2012م)، وتثريري مجلس الدولة حول متابعة أداء قطاع التعليم العام ومتابعة أداء قطاع التعليم العالي خلا لالم الأربع سنوات الأولى من الخطة الخمية السابعة (2006-2010م). وتقرير التنافسية العالمية (2012م)، وتقرير التمية البشرية (2012م)، ودراسة إعادة منظومة هيكلة التعليم التي أعدها مجلس التعليم (2013م)، ونوجهات المجلس الأعلى للتخطيط. ومن بين أهم التحديات المتعلقة بإدارة التعليم في السلطنة توفير فرص التتمية الإدارية للكوادر الإدارية في قطاع التعليم، وغياب التوصيف الدقيق لمسؤوليات ومهام مجالس الإدارة ومجالس الأمناء والإدارة التنفيذية في مؤسسات التعليم العالي الخاصة مما يؤثز على كفاءة الأداء الإداري

وبغية مواجهة تللك التحديات بدأت السلطنة في عام 2012 مرحلة جديدة من التتمية وعملت على صياغة أهداف وطنية تسعى إلى تحقيقها في إطار خطط التتمية المستدامة. وفيما يخص قطاع التعليم فإنها تسعى إلى انتهاج سياسات وآليات عملية منكاملة لتحقيق الأهداف الوطنية للتمية المستدامة من خلا لتمية الموارد البشرية لتأخذ دورها في القرن الحالي؛ والذي يشهد منافسة تعتمد على العلم والمعرفة. كما أنّ نطبيق الإسنراتيجية بحاجة إلى رفع الكفاءة الإدارية التي تساعدها في إدارة شؤونها وتحسين النوعية في الجوانب التي تقع إنع

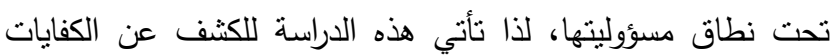
اللازمة للقيادات الأكاديمية بكلية التربية بجامعة السلطان قابوس في ضوء رؤية إستراتيجية التعليم بالسلطنة 2040.

\section{مشكلة الدراسة وأسئلتها}

تتمنل مشكلة الدراسة في البحث عن الكفايات اللازمة للقبادات الأكاديمية بكلية التربية بجامعة السلطان قابوس في ضوء رؤية إستراتيجية التعليم 2040، وذلك لإدراك الجامعة للاور الكبير الذي يقوم به هؤلاء القادة لقيادة مسيرتها نحو التقدم، وبما يحقق أهدافها ويضمن لها استدامة واستمرارية التطور والنمو والبقاء ويجعلها في مصاف الجامعات العالمية، من هنا جاءت هذه الدراسة لتجيب عن

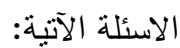


جدول (1) توزيع أفر اد عينة المقابلة حسب الوظيفة

\begin{tabular}{|c|c|c|}
\hline النسبة المئوية & العدد & الوظيفة \\
\hline$\% 22$ & 2 & عميد كلية \\
\hline$\% 34$ & 3 & مساعد عميد \\
\hline$\% 22$ & 2 & مدير دائرة \\
\hline$\% 11$ & 1 & رئيس وحدة \\
\hline$\% 11$ & 1 & رئيس قسم \\
\hline$\% 100$ & 9 & المجموع \\
\hline
\end{tabular}

أداة الاراسة: تم إعداد بطاقة الدقابلة وقد تضمنت بيانات

المقابلة، والبيانات الثخصية للمبحوثين، وكذلك خطوات إجراء المقابلة، وخمسة أسئلة مفتوحة وموجهة للمبحوثين.

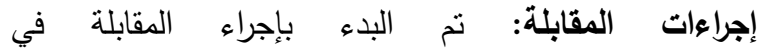
(2019/11/13) واستمرت عملية جمع البيانات من المبحوثين لغاية (2019/12/9) أي حوالي مدة شهر تقريبا.

المعالجة الإحصائية: تمت معالجة البيانات الميدانية باستخدام

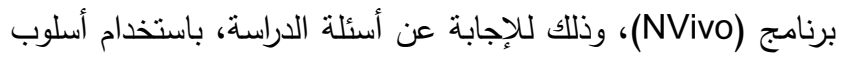
الترميز لاستجابات افراد عينة الدراسة.

\section{نتائج الداسة ومناقشتها}

سيتم عرض نتائج الدراسة وفقا لنسلسلها:

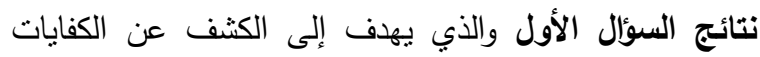

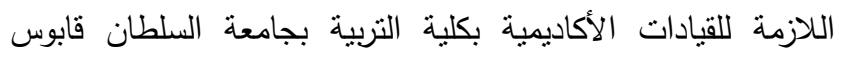
بسلطنة عُمان في ضوء رؤية استراتيجية التعليم 2040 من وجهة نظر عينة الدراسة.

للإجابة عن السؤال الأول، تمّ إجراء تحليل المضمون باستخدام

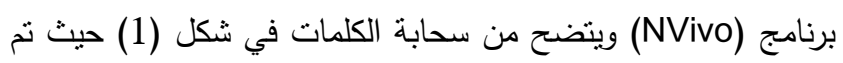
اعنماد معيار وقدره ثناثة نكرارات للمفهوم الذي بعكس الكفاية كد

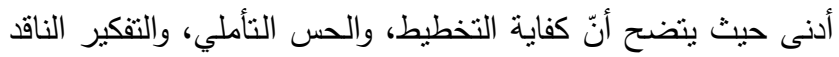

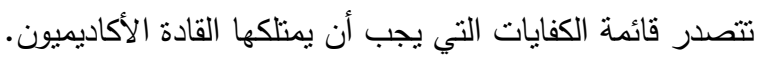

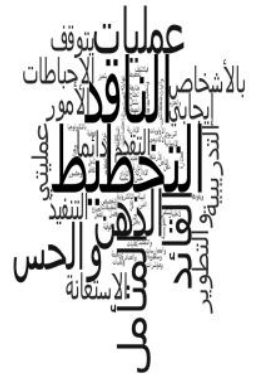

شكل 1: السحابة الكلامية للكفايات الأكاديمية التي وردت في استجابات

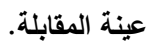

\section{مصطحات الدراسة}

Samara \& Al-) الكفايات Competences: يعرّف

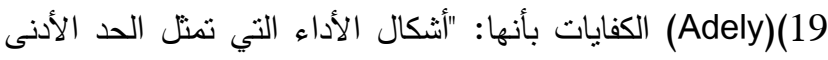

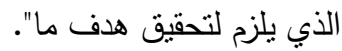

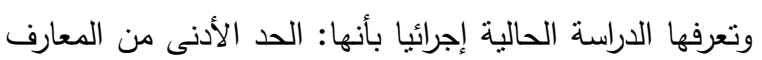

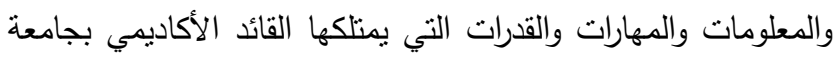
السلطان قابوس والتي تجعله قادرا على أداء عمله بكفاءة وفاعلية. القيادات الأكاديمية Academic leaders: يعرّف ( Jamal (Al-Din, Al-Suwaidi \& Hassanein)(13 على أنهم "مجموعة القيادات الذين يشغلون المناصب الإدارية ذات

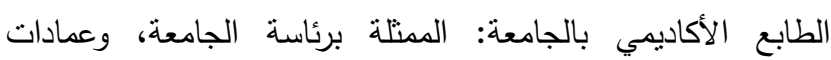
الكليات، ورئاسة المجالس العلمية، بوصفهم من أهم العناصر المناطة بها إدارة المؤسسة الجامعية فهم مسؤولون مسؤولية مباثرة عن تسيير العملية الإدارية داخل الجامعة حسب المهام والاختصاصات المخولين بها للسعي في تحقيق وظائف الجامعة والوصول إلى أهدافها.

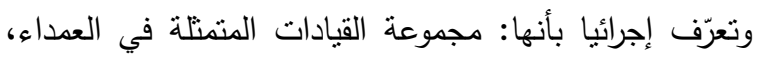
ومساعدي العداء، ومديري الدوائر، ورؤساء الأقسام، ورؤساء الوحدات بجامعة السلطان قابوس ممن يمتلكون المسؤولية لتسيير العملية الإدارية داخل الجامعة حسب المهام والاختصاصات المنوطة الهنة بهم سعيا لتحقيق أهداف الجامعة.

الطريقة والإجراءات

يتناول هذا الجزء وصفا لمنهج الدراسة ومجتمع الدراسة والعينة

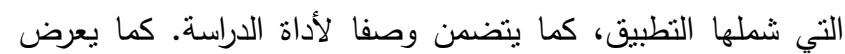
أيضا إجراءات الدراسة ومعالجة البيانات للإجابة عن الأسئلة.

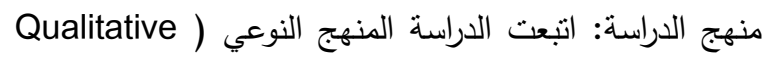
لتحقيق أهدافها، وقد اتبعت أسلوب تحليل المحتوى النوعي (method (Qualitative Content Analysis) النصية في المنهج النوعي، حيث يتم جمع البيانات المناسبة، ومن ثم

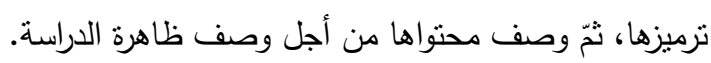

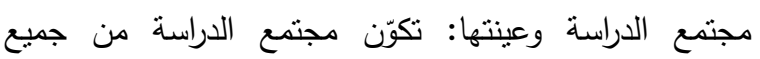

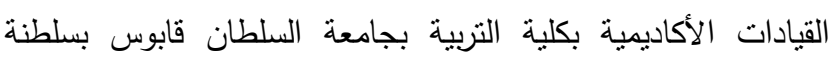
عُمان منمثلة في عميد الكلية وعميد القبول والتسجيل وثمانية أقسام

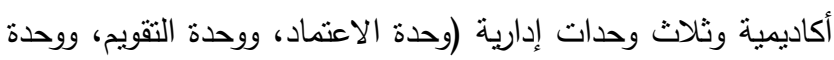

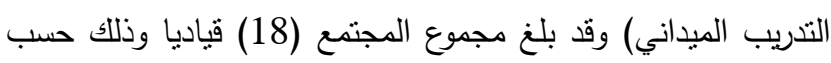

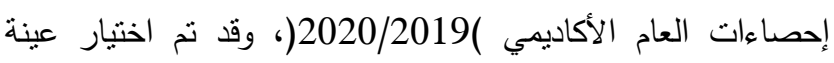
قصدية للمقابلة وقد تم أخذ موافقتهم في المشاركة بالدراسة وكما هو موضح في جدول (1). وبعد أن تمت عملية التحليل بشكل عام، تم تصنيفها في مجالات للكفايات وكما هو موضح في جدول (2). 
جدول (2): الكفايات التي وردت في استجابات افراد عينة الدراسة

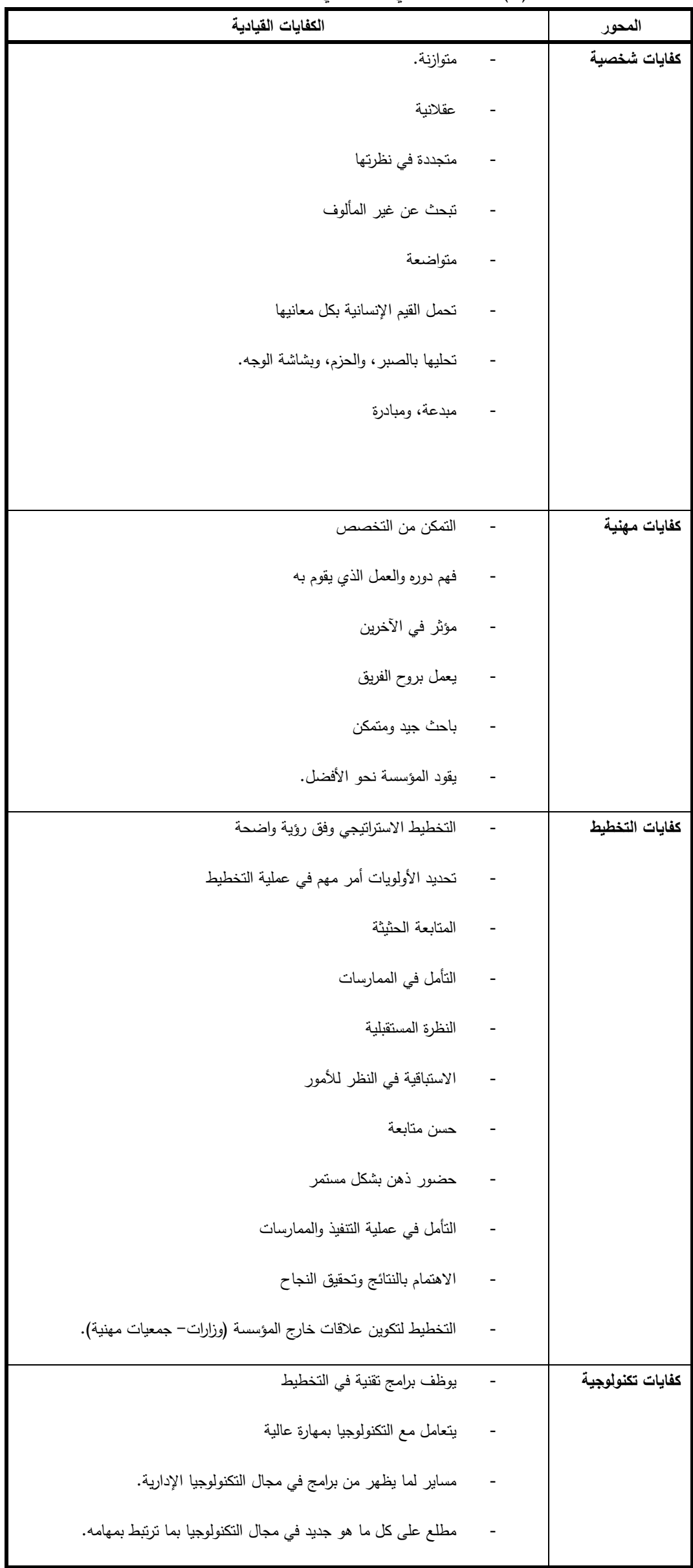


5. الإنماء الذاتي: هناك أشخاص تتاح لهم الوصول إلى مناصب

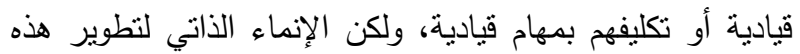
الكفايات يعود للثخص نفسه حتى يمكن أن نطلق عليه اسم قائد.

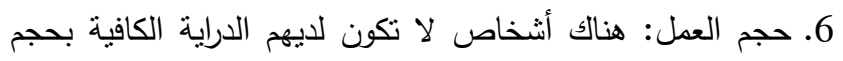

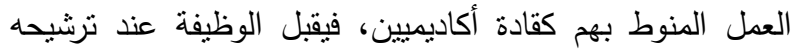
لها، ثم يتفاجأ بحجم العمل وتبدأ الإخفاقات، ويبدأ الفتور في العمل

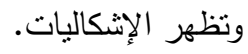

كما أظهرت النتائج أن مصدر هذه المعوقات التوات هي:

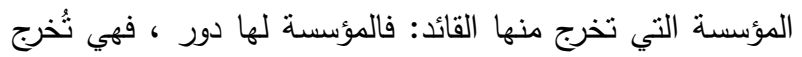

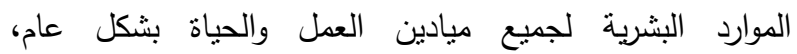

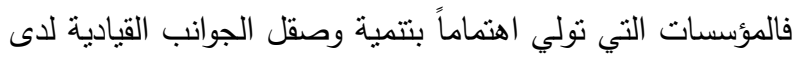
طلبتها ييرز ذلك المجهود من خلال الكفايات التي يمنلكها خريجوها. فمثلا في جامعة السلطان قابوس سابقا كان الاهتمام بتكوين أو تخريج قيادات لم يكن بالثكل الكبير والملحوظ، ولكن بفعل ما يتم فيها من حراك علمي ونشاط أصبح الآن الاهنمام بتكوين قيادات أكبر عن السابق. بيئة العمل: عدم نوفر البيئة المناسبة لتتمية المهارات والكفايات وعدم إتاحة الفرص للمشاركات المختلفة التي تصقل المهارات التي يحتاجها الثخص كقائد، والثردد والتخوف من تحمل المسؤوليات؛ فعلى الثخص ليكون قائدا أن يستقرأ المجالات التي تؤهله للتحويل

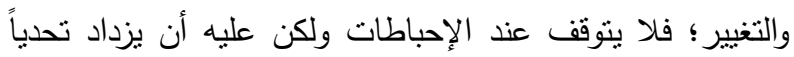

$$
\text { وطموح أورغبة في العطاء، وعليه أن يبحث. }
$$

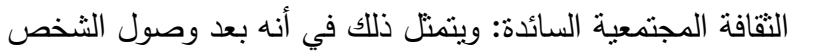
إلى منصب قيادي تصبح له مكانة فوقية حيث يلاحظ تبجيل المجتمع له، فبالتالي تصبح الوظيفة (Prestige) وقد تسهم المؤسسة في تفاقم ذلك لعدم وجود المساءلة والمحاسبة والمتابعة. نتائج السؤال الثالث والذي يهذف إلى التوصل إلى وضع مجموعة من الإجراءات المقترحة لنطوير كفايات القادة الأكاديميين بكلية التربية بجامعة السلطان قابوس، وكان أبرز ما توصلت إليه

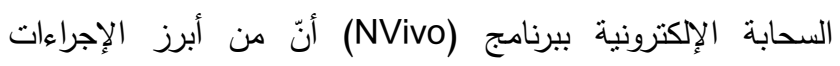

المقترحة لتطوير كفابات القادة الأكاديميين بكلية التربية ما يلي:

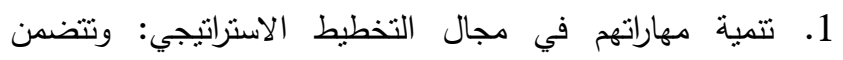
مهارات وآليات وتقنيات التخطيط، ومؤشرات الأداء. 2. تتمية مهارات التأمل: فعمليات التخطيط والتتفيذ تحتاج إلى عملية تأمل في الممارسات التي تتم وتقييمهما وتعديل مسارها لتحقيق التيق

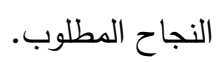

3. تتمية دهارات النواصل: لكي نكون البرامج التدريبية المتعلقة بالنواصل فاعلة لا بد تكون مشبعة بلعب الدور (Role play)

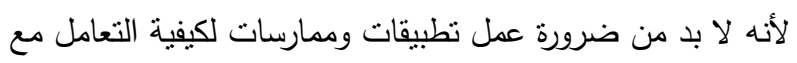

$$
\text { الآخرين في المواقف المختلفة. }
$$

توضتح النتائج في جدول (2) أنّ هناك أربعَ كفايات أساسية أظهرتها نتائج تحليل المقابلة والني لابد وأن يمتلكها القادة الأكاديميون

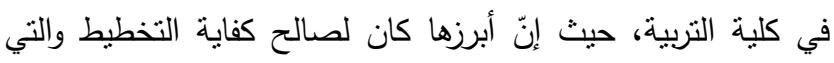

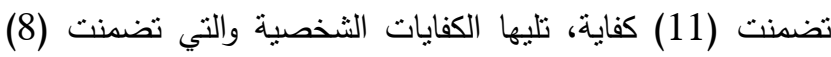
كفايات، ثم الكفايات المهنية (6) كفايات، وأخيرا الكفايات التكنولوجية والتي بلغ عددها (4) كفايات. والثكل (2) يوضح الاتجاه العام للكفايات.

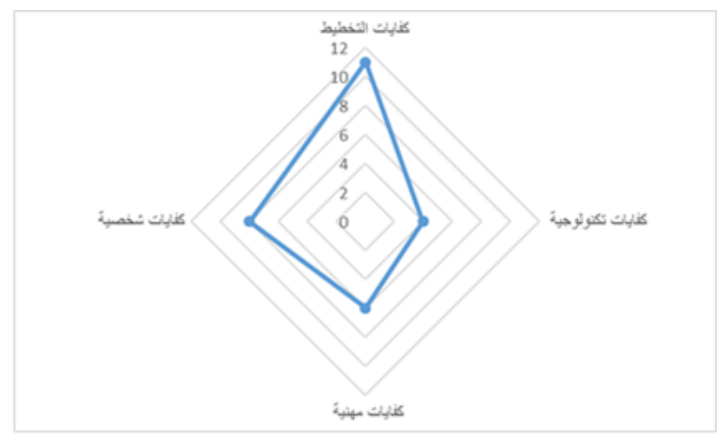

شكل (2) يوضح الاتجاه العام لكفايات القادة الأكاديميون

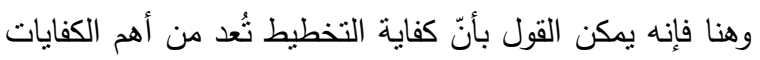
التي أظهرتها نتائج الدراسة، تليها الكفايات الثخصية، ثم الكفايات المهنية، وأخيرا الكفايات التكنولوجية. نتائج السؤال الثاني والذي يهدف إلى الكثف عن المعوقات التي تواجه القادة الأكاديميين في تمثل الكفايات اللازمة للقيادات الأكاديمية في ممارساتهم الأكاديمية بكلية التربية بجامعة السلطان

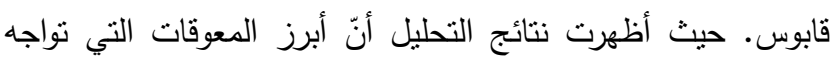

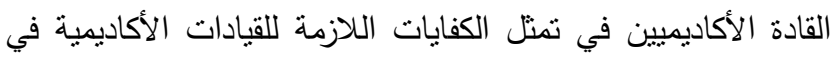

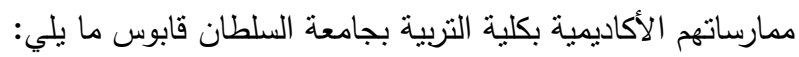

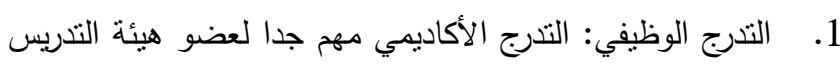

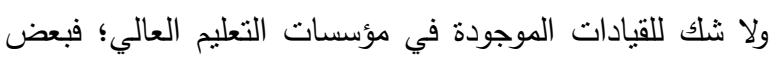

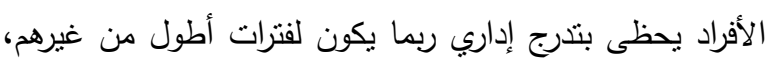

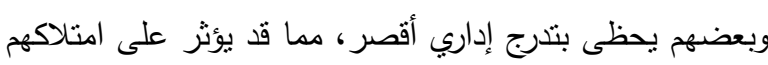

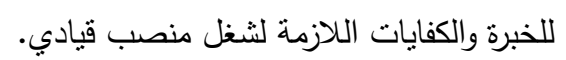

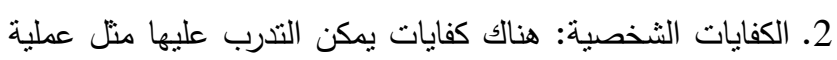

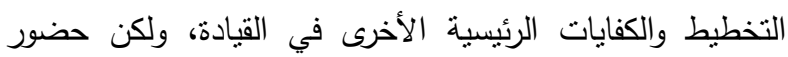

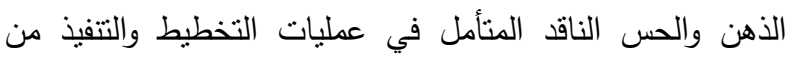
الصعب تعلمها مما يسبب في إخفاق بعض الأثخاص عند نوليهر مهامّ قيادية. 3. التأهيل: لا يحظى القائد الأكاديمي في الجامعة بفتزة تأهيل قبل نوليه المنصب القيادي ولا بعد مباشرته لمهامه.

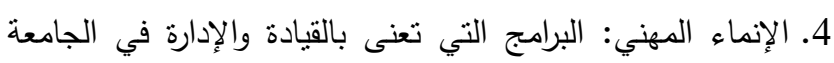

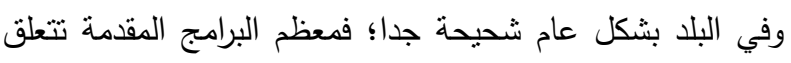

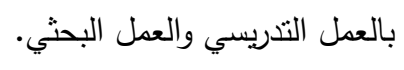


كل سنة نجتمع في الكلية من أعضاء هيئة التدريس وأكاديميين وإداريين وفنيين في مكان نختاره وندعو بعض الطلبة وندعو بعض فل المستقيدين من خارج الجامعة شركاؤنا من وزارة التربية والتعليم

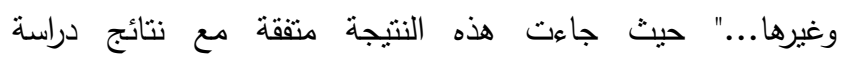
(7)(Bubshait) باعنبارهما من الكفايات الأساسية والمهمة في العمل القيادي.

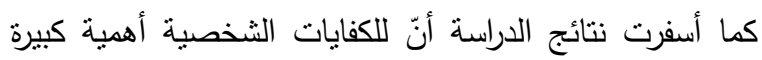
أيضا، حيث جاءت بالمرثبة الثانية، وأظهرت العديد من السمات والخصائص الثخصية التي لابد من أن يمتلكها القادة الأكاديميون

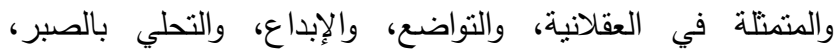
والمبادرة، والتجديد، والبحث عن غير المألوف، وبشاثة الوجه وغيرها من سمات الثخصية والتي نم ذكرها في جدول (1). وهذا ما أكده المستجيب (م/1): "يحتاج القائد إلى كفايات شخصية: منوازنة، عقلانية، متجددة في نظرتها، تبحث عن غير المألوف، منواضعة، تحمل القيم الإنسانية بكل معانيها، الإيمان بالنسبة لي ركيزة أساسية بالنسبة لي، الصبر ، الحزم و ...". وفي ذات السياق أضاف المستجيب (م/2): "'أنا أؤمن أنّ عدداً

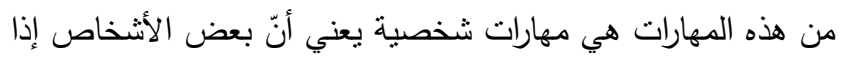

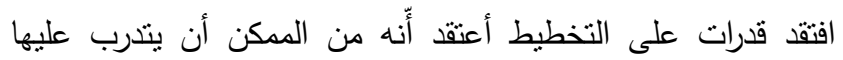
ويدربوه كيف يخطط وهكذا.. لكن في النهاية لا بد أن يكون ذهنه وعقله /ORIENTED موجهة على عملية التخطيط.. بمعنى لازم يكون عقله بالفعل يخطط صح.. عقل متابع.. عقل ناقد.. عقل

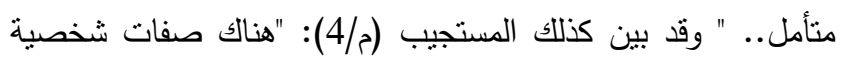

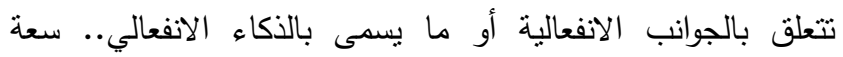

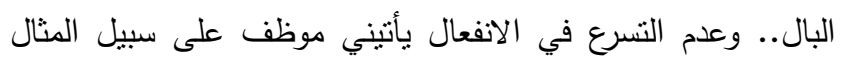

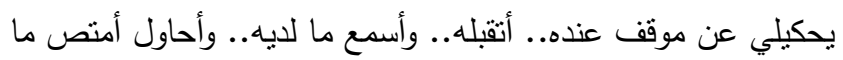

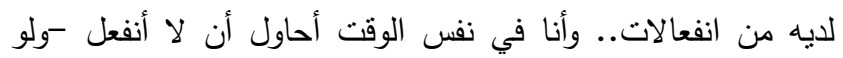
كنت فظا غليظ القلب لانفضوا من حولك- - فهذه قاعدة في الذكاء

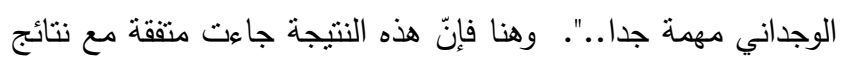
دراسة (Ogaldez \& Hilton) في مأنة القيادات الإدارية لابد وأن

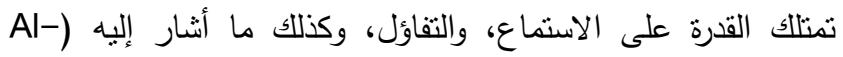
(Mahadin \& Battah بأخلاقيات المهنة وخاصة تلك المرنبطة بالجوانب الثخصية.

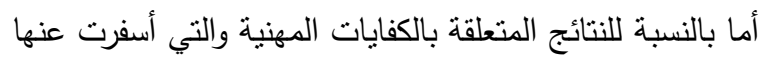

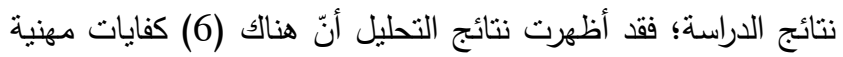
تمحورت حول التمكن من التخصص حيث ذكر المستجيب (م/1):

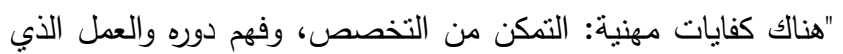
يقوم به، ويكون قيادي يؤثر على الآخرين ويعمل بروح الفريق ويبتحد

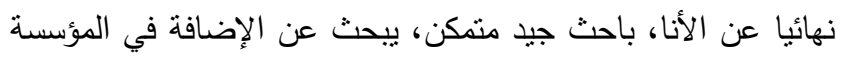
التي يعمل بها ويقودها نحو الأفضل". وأثنار إليها المستجيب (م/3): "القائد الأكاديمي إذا فعلاً نحن نختار القائد الأكاديمي حسب الأبل
4. تقديم دورة مكثفة لإعداد القادة: وتتضمن التدريب على المهارات وبرامج التمكين في مجالات عدة مثل: (إدارة الملفات، التطبيقات الإككترونية، المراسلات، التخزين، صنع القرار، قواعد اليبانات،

وضع إحصائيات، الأرشفة، وضع نصور مستقبلي، التحليل).

\section{مناقشة النتائج والتوصيات}

$$
\text { سيتم مناقتنة نتائج الأسئلة وفقا لتسلسها: }
$$

السؤال الأول: ما الكفايات اللازمة للقيادات الأكاديمية بكلية التربية بجامعة السلطان قابوس بسلطنة عُمان في ضوء رؤية

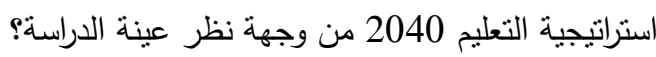

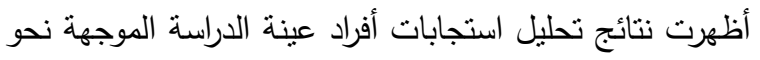

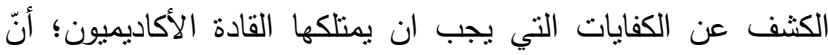
هناك العديد من الكفايات الأساسية التي بلغ مجمل عددها (29) كفاية موزعة على أربعة مجالات هي كفايات التخطيط، وكفايات مهنية، وكفايات شخصية، وكفايات تكنولوجية.

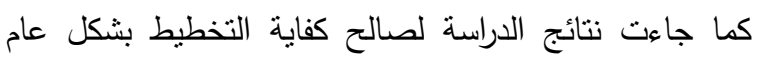
والتخطيط الاستراتيجي بشكل خاص، وكفاية تحديد الأولويات، والنظرة

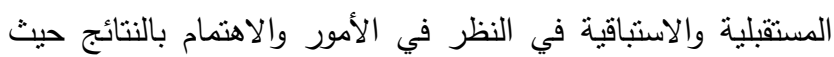

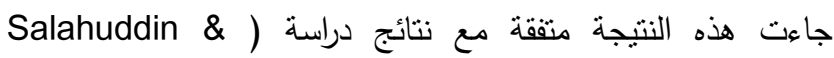
(Attia مجالات النوجه الاستباقي خاصة في إدارة الأزمات، وقد تم الإثشارة من قبل المستجيب (م/2) الى هذه الكفاية في قوله: "أهم مهارة

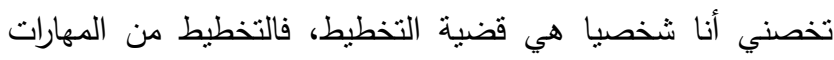

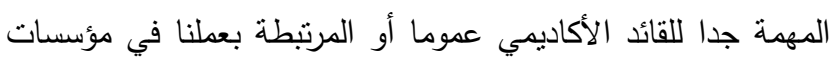
التعليم العالي"، كما أضاف: "التخطيط الاستراتيجي مهم جداً للقادة.. التخطيط الاستراتيجي بشكل عام، مهارات وآليات وتقنيات التخطيط الاستراتيجي هذه جداً مهمة.. وطبعاً يتصل بها قضية المؤشرات.

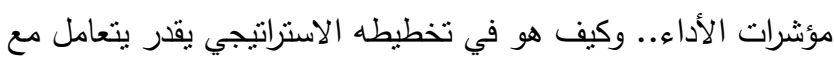

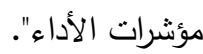

كما أكدّ ذلك المستجيب (م/4) "مهارة التخطيط الاستراتيجي خاصة فيما يتعلق بوضع الخطط الاستراتيجية والخطط التنفيذية لها..

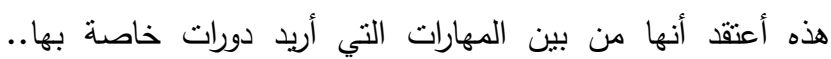
اكتسبتها الآن من خلال العمل.. لكن كنت ارغب أحضر ورش كهذه". وهذا بشير إلى أهمية هذه الكفاية للقياديين الأكاديميين. كما

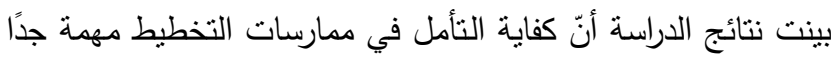

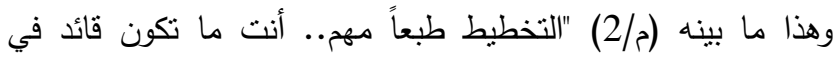

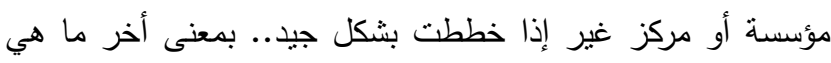

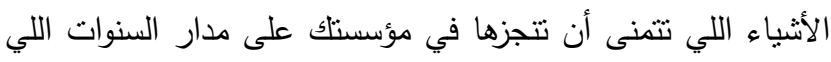
تكون موجود فيها؟...". وأضاف: "... ونحن في الجامعة لا نمارس لاس لإس التأمل في أذهانتا فقط ولكن خصصنا في العام الدراسي وقتنين رئيسيين للتأمل في ممارساتتا، وهو اليوم المفتوح في فصل فئل الربيع من فئن 
Shahnandi, Silong, Ismail, ) هذه النتائج متنقة مع ما ذكره منطم) (20) في أهمية وجود برنامج إنمائي تطويري (abu Samah, Othma

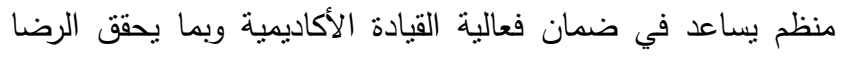

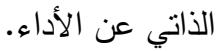

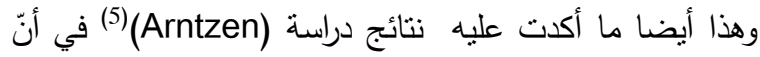

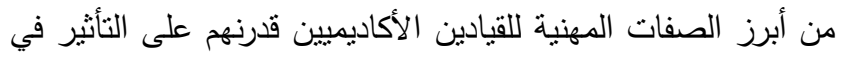
الآخرين، إضافة إلى امتلاكهم للقدرات البحثية التي أثنار إليها

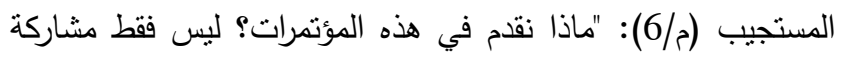

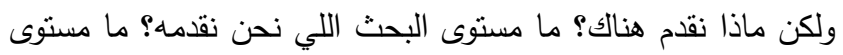
البحث اللي نحن ننشره؟ هذه كلها لها معاني كبيرة جدا.. وهذا كله

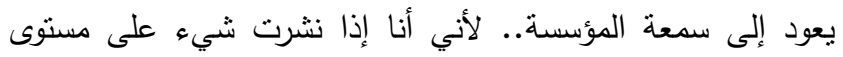

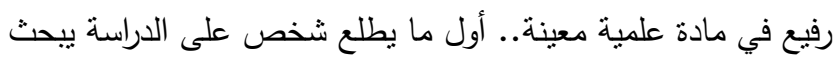
نشرت من أي دولة ومن أي مؤسسة؟". أما بالنسبة إلى النتائج المتعلقة بالكفايات التكنولوجية أظهرت

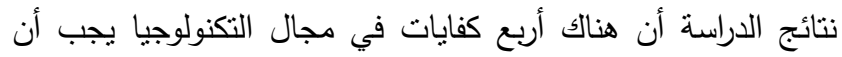

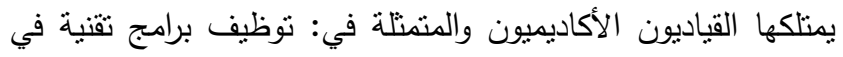

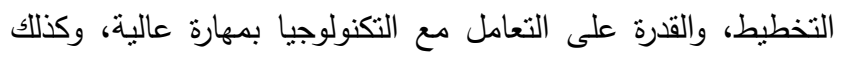

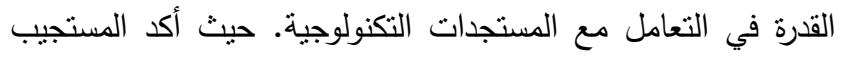
(م/1): "بلزم على القائد في هذا العصر التعرف على كل ما هو جديد

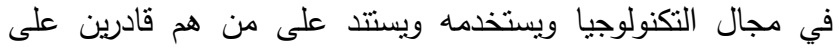
ذلك"، وكذلك المستجيب (م/5): "من البرامج الضرورية للقائد كيفية

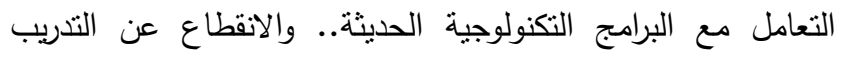

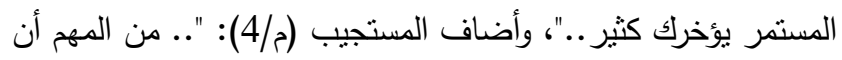

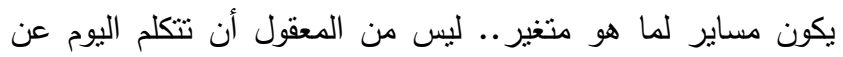
التكنولوجيا بعقلية قبل عشرين سنة". وهنا فإنه يمكن القول بأن للتكنولوجيا أهمية كبية كبيرة في

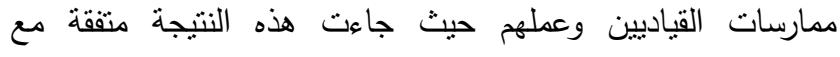
التوجهات المستقبلية لروئة عُمان للاقتصاد 2020 في أهمية تكوين موارد بشرية مواكبة للنطور الثقني والتكنولوجي، وهذا ما أكد عليه (1) في أنّ القائد الأكاديمي لا بد وأن يمثلك مهارة (Abdul Rahim)

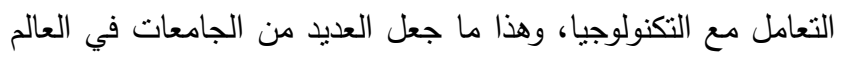
تحرص على تقديم العديد من الدورات التدريبية لتأهيل القياديين في

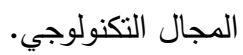
السؤال الثاني: ما المعوقات التي نواجه القيادات الأكاديمية في تمثل الكفايات اللازمة للقيادات الأكاديمية في ممارساتهم بكلية التربية

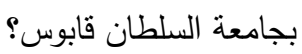
بالنسبة لنتائج السؤال الثاني المتعلقة بأبرز التحديات التي نواجه

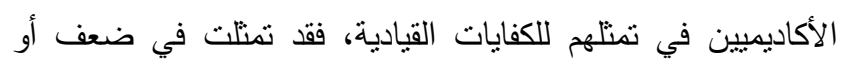

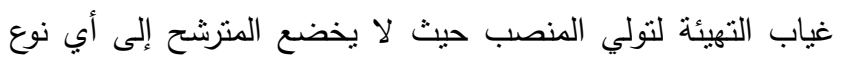
من التأهيل القيادي والذي يمكن أن يساعده في مهامه القيادية وهذا ما لإيا بينه (م/5): "طبعاً هناك بعض الأمور الإدارية يحتاج فيها القائد
مواصفات معينة لا بد أن يكون منغمس ومنعمق في الجانب التربوي

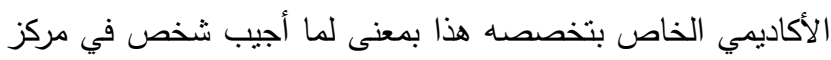

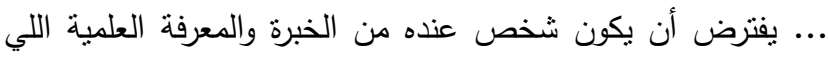

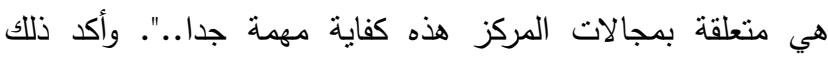

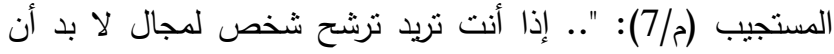

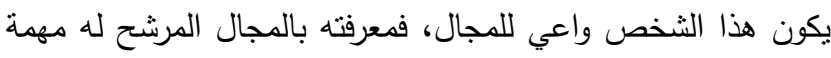
جدا كتخصص.. فالجانب الأكاديمي جدا مهر". وكذللك كفاية فهم الدور والذي يقوم به القياديون الأكاديميون وهذا ما أنثار اليه المستجيب (م/4): " فقبل أن أجي هنا كان الزميل لهيل

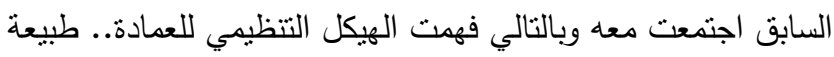

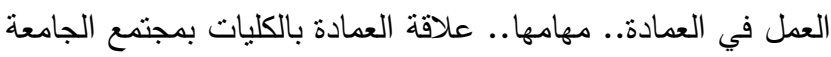
ككل.. يعني من هم الموظفين اللي راح أنعامل معهم.. خصائصهم.. العلاقات فيما بينهم.. فأخذت فكرة مبدئية في هذا النوع من التهيئة

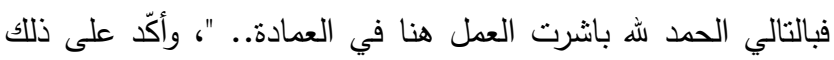

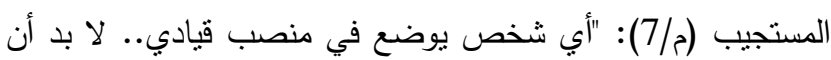

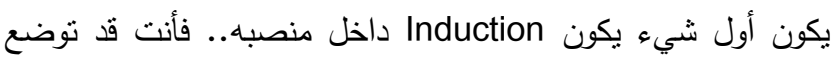
في دوضع أنت لا تعرف أين تقع فيه فأول شيء أعرفه بمسؤولياته وواجباته.. أيضا المعرفة بالآليات المتبعة ونظام العمل...". إضافة إلى كفاية العمل بروح الفريق وامتلالك القدرات البحثية

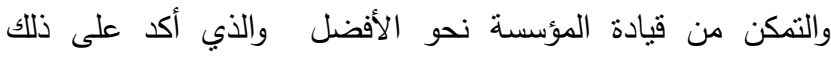
المستجيب (م/3): "يتطلب قيادة هذه السفينة تعاون.. يتطلب من القائد

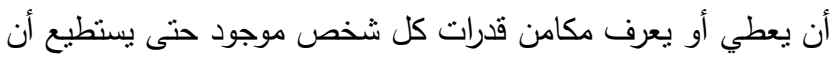

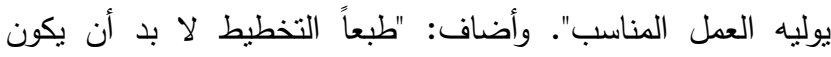

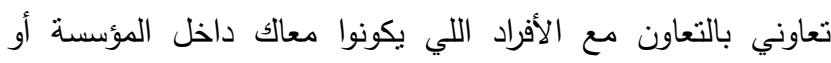

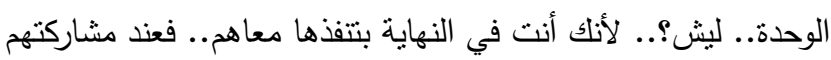
هذا من شأنه إصلاح ما في الوحدة وتكون عملية الإصلاح وعملية

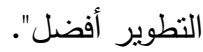
وفي نفس السياق أكد المستجيب (م/4): ".. أول ما بدأت كانت فيه لقاءات مكثقة مع جميع موظفي العمادة.. هذا ما لمسته سابقاً

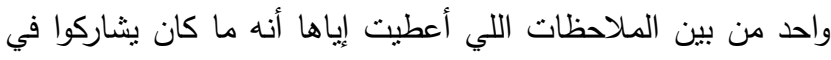

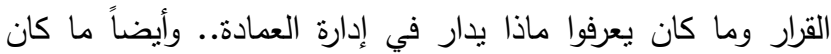

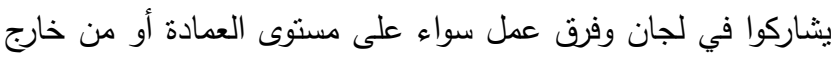

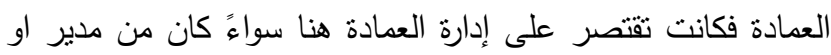

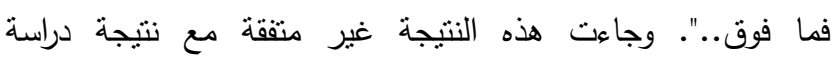
(Gonzalez \& Sutton)

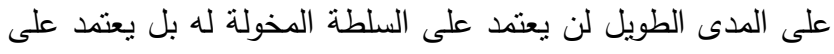

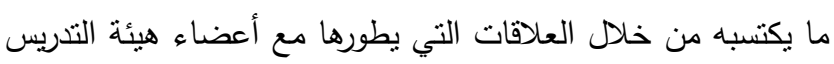
والطلبة والمشرفين الإداريين؛ وكذلك مع نتائج دراسة (9) (hamroon) في أنّ إثراك أعضاء هيئة التنريس عند التخطيط والنطوير وإثناعة الحرية والاستقال بالراي هي من أهم الممارسات التي نساعد في

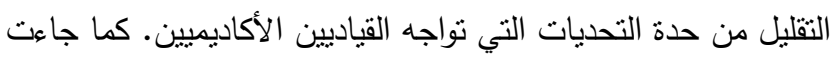


مسؤول إداري...". في حين أوضح المستجيب (م/4): "أنا من بين الدورات التي كنت أطدح في الحصول عليها من بينها.. كيفية إدارة الانفعالات سواء من قبل العملاء أو من قبل الموظفين... ومهارة التخطيط الاستراتيجي خاصة فيما ينعلق بوضع الخطط الاستراتيجية

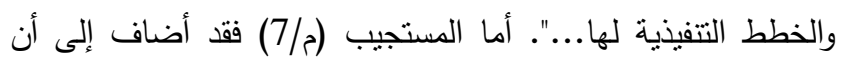
القائد يحتاج أيضا للتنريب على: "الجانب المنعلق بإدارة الوقت جدا

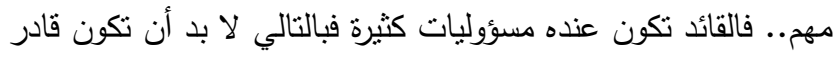

تضبط وقتلك أو نوفر أثخاص يساعدوك في إدارة الوقت..." وخلاصة النتائج فإنه يمكن القول بأنّ معظم استجابات أفراد عينة الدراسة على السؤال الأول والمتعلق بالكفايات اللازمة للقيادات الأكاديمية بكلية التربية بجامعة السلطان قابوس بسلطنة عُمان في ضوء رؤية استراتيجية التعليم 2040، فقد تمثلت فيما يلي: بلئ - - كفايات التخطيط، وما برتبط بها مهارات وأليات وتقنيات، وذلك يتضمن وضع الخطط الاستراتيجية والخطط التتفيذية، وعمليات التأمل والتقييم المرتبطة بكفاية التخطيط. كفايات مهنية، وتتعلق بالتمكن من التخصص

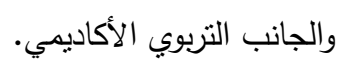

- كفايات شخصية، بحيث تكون شخصية منوازنة، وعقلانية، ومتجددة في نظرتها، وتبحث عن غير

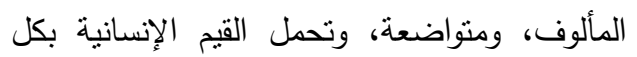

$$
\text { معانيها. }
$$

- - كفايات تكنولوجية، حيث يلزم على القائد في هذا العصر التعرف على كل ما هو جديد في مجال التكنولوجيا ويستخدمه ويستت على من هم قادرون

$$
\text { على ذلك. }
$$

كما تمنلت استجابات أفراد عينة الدراسة المتعلقة بالمعوقات التي تواجه القادة الأكاديميين في تثثل الكفايات اللازمة للقيادات الأكاديمية في ممارساتهم بكلية التربية بجامعة السلطان في الآتي:

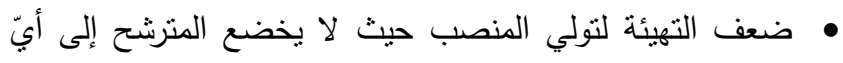
نوع من التأهيل القيادي والذي يمكن أن يساعده في مهامه

$$
\text { القيادية. }
$$

• حجم العمل ونوع الصلاحيات الممنوحة وبعض ما يواجه القيادي من إخفاقات عند ظهور بعض الإشكاليات.

• المحاباة، واختيار الأثخاص على عسب الهب المعرفة الثخصية.

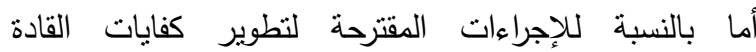
الأكاديميين بكلية التربية بجامعة السلطان قابوس فقد تمنلت في الآتي:

• برامج تتعلق بالتخطيط الاستراتيجي وإعداد الخطط التتفيذية.

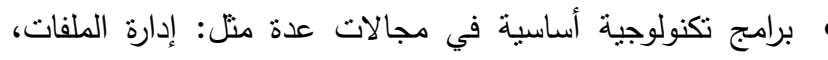

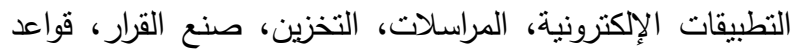

لدورات تدريبية مثل التعامل مع ضغوط العمل والتعامل مع وسائل

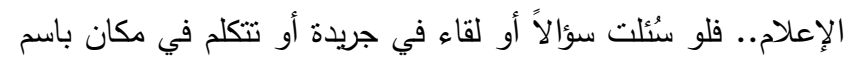

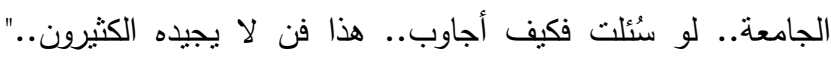
وأضاف إليه (م/3): "...الكفاية الثانية وهي مهمة أيضاً بل مهمة جداً

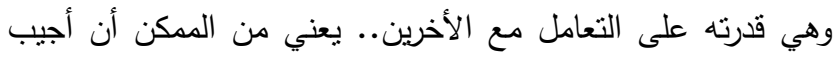
قائد يدير مجموعة وهو ليس مؤهل من ناحية قدرته على التعامل

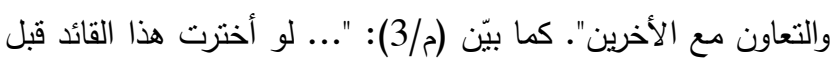

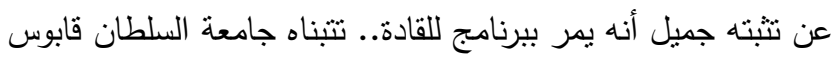

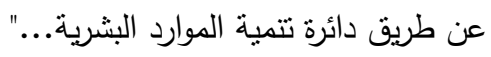

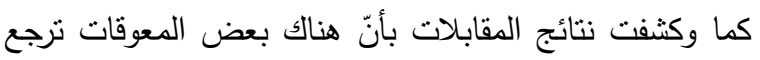

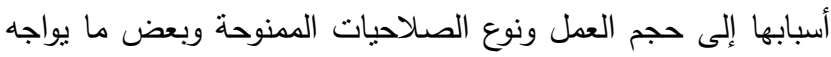
القيادي من إخفاقات أثناء العمل وظهور بعض وناع الإثكاليات وهذا ما لها

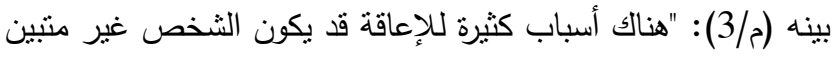

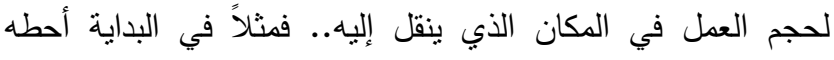

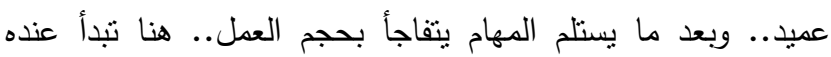
إثنكالية أو إخفاقات..". السؤال الثالث: ما الإجراءات المقترحة لتطوير كفايات القيادات

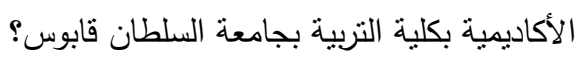

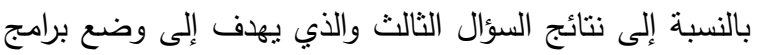

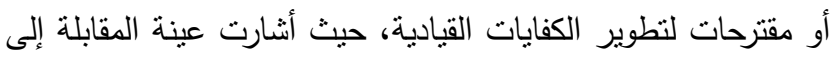

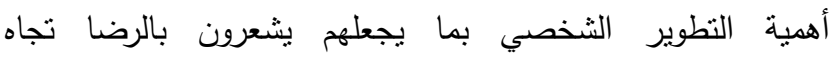

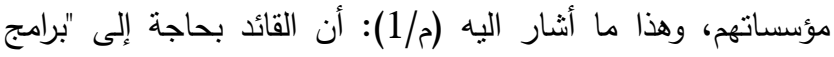

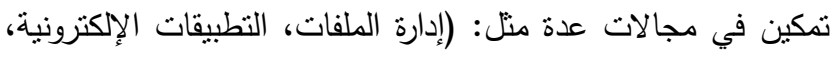

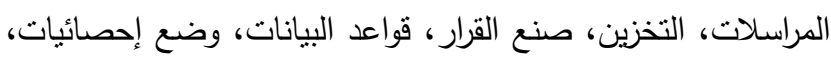

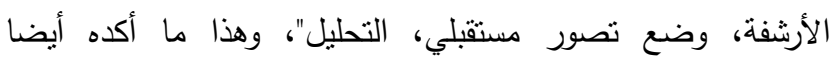

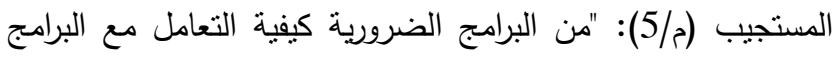

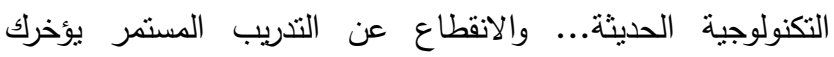

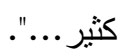
وأضاف المستجيب (م/2): أن القائد بحاجة إلى برامج نتعلق ب:

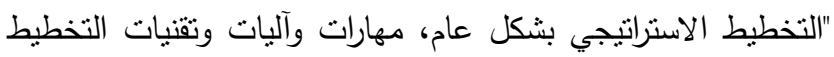
الاستراتيجي هذه جداً مهمة.... وطبعاً بنصل بها قضية المؤشرات... مؤشرات الأداء... وكيف هو في تخطيطه الاستراتيجي يقدر يتعامل

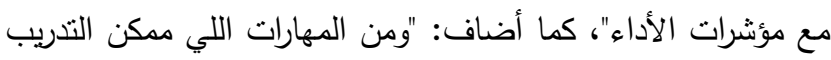

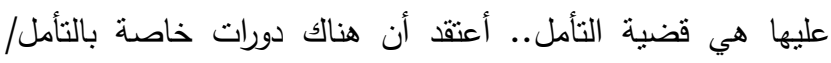
Reflection

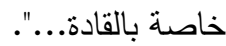
وبالنسبة للبرامج التي يحتاجها القائد ذكر المستجيب (م/3):

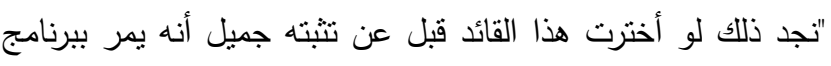

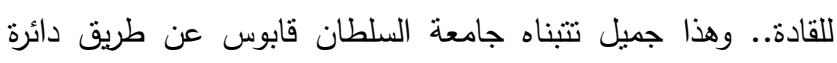

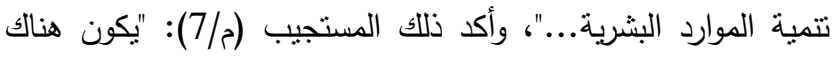

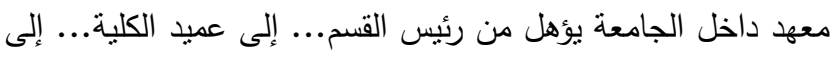


universities to professional ethics from the viewpoint of faculty members. Journal of Studies-Educational Sciences. Jordan, 45 (4): 256-277. (2018)

4. Ali, Saeed Ismail. For leadership to be educational. The fifteenth annual conference, Qualifying Educational Leaders in Egypt and the Arab World, the Egyptian Association for Comparative Education and Educational Administration and the University Education Development Center at Ain Shams University. January, 477-493. (2007)

5. Arntzen, Eystein. The Changing Role of Deans in Higher Education - From Leader to Manager. Universal Journal of Educational Research, 4 (9): 2068 - 2075. (2016)

6. Board of Education. The National Education Strategy 2040. The General Secretariat of the Education Council. (2014)

7. Bubshait, Al-Jawhara Ibrahim Muhammad. The extent to which academic administrative leaders at the University of Dammam practice transformational leadership. Journal of the College of Education. Ain-Shams University, 2(37): 339-361. (2013)

8. Gonzalez, Gerardo and Sutton, Margaret. The Role of Supportive Leaders At Top Performing Universities: Best Practice Lessons from American Institutions for Indonesian Higher Education. International Journal of Leadership and Change, 1 (1): 5 13. (2013)

9. Hamrun, guest of God Bani Ghadyan bin Suleiman. Performance management among academic leaders at the University of Tabuk: a field study. Journal of the Arabian Gulf message, 32 (119): 85-134. (2011)

10. Hashem, Nahla Abdel Qader. Developing the performance of Egyptian universities in the light of strategic quality management. Journal of Education, Egyptian Association for Comparative Education and Educational Administration, 23 (11): 283-375. (2008)

11. Hassan, Nahla Sayed. Developing strategic leadership skills for academic leaders in Egyptian universities in light of the applications of some foreign universities. Educational and social studies. Egypt, 19 (4): 377-440. (2013)

12. Hegazy, Bassam Ahmed. Qualifying administrative and academic leaders in universities and developing human resources. The Arab Forum on International Standards for Universities, Arab Administrative

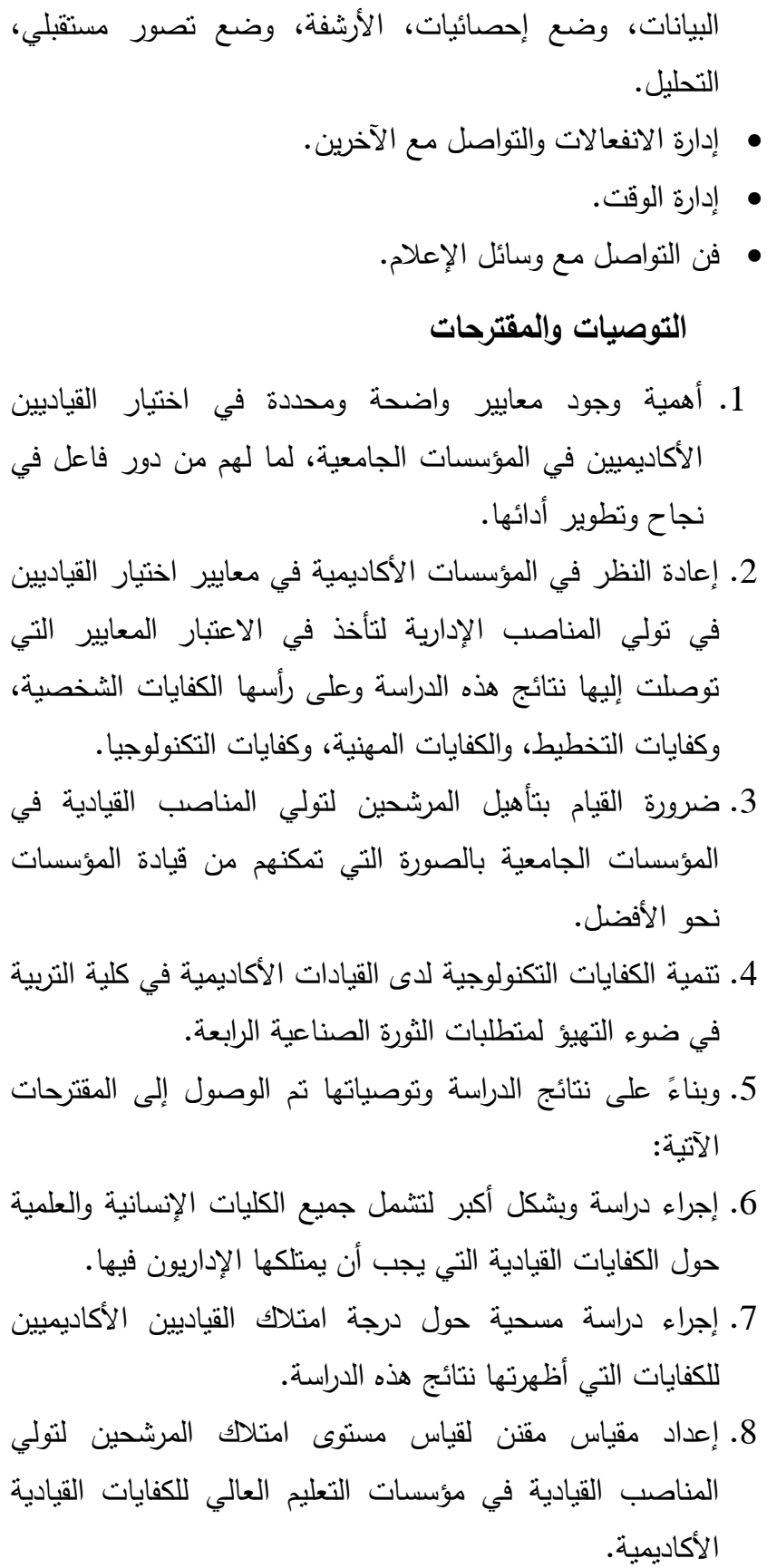

\section{References}

1. Abdel Rahim, Sameh Jamil. Qualifying academic university leaders. The fifteenth annual conference, Qualifying Educational Leaders in Egypt and the Arab World, the Egyptian Association for Comparative Education and Educational Administration and the University Education Development Center at Ain Shams University. January, 143-132. (2007)

2. Abdul Hadi, Princess Ramadan and Hatata, Umm Al-Saad. Empowering academic leaders at Kafrelsheikh University: a case study. World Council of Societies of Comparative Education. Egypt, 15 (35): 201-279. (2012)

3. Al Mahadin, Naila Abdel Salam and Battah, Ahmed. The degree of commitment of academic leaders in public Jordanian 
International Journal of Business Administration, 2 (1): 44 - 53. (2011)

21. Siddique, Anam; Aslam, Hassan; Khan, Mannan and Fatima, Urooj. Impact of Academic Leadership on Faculty's Motivation and Organizational Effectiveness in Higher Education System. International Journal of Business and Social Science, 2 (8): 184 - 191. (2011)

22. Yaghi, Mohamed Abdel Fattah. Theoretical and practical training. Ahmed Yassin Technical Center - Jordan. (2003)
Development Organization. September, 287311. (2003)

13. Jamal Al-Din, Najwa Youssef, AlSuwaidi, Mabrouk Saleh and Hassanein, Muhammad Refaat. The effectiveness of administrative development in developing the performance of academic leaders in universities. New Horizons in Adult Education, Ain Shams University, Adult Education Center, (23): 9-41. (2018(

14. Kaddouri, Faeq Mishaal. Choosing academic leadership in the Iraqi experience: a strategic vision. The Arab Forum for Developing the Performance of Faculties of Management and Commerce in Arab Universities. Arab Organization for Administrative Development. 108-132. (2003)

15. Morris, Tracy L and Laipple, Joseph S. How prepared are academic administrators? Leadership and job satisfaction within US research universities. Journal of Higher Education Policy \& Management, 37(2): 241251. (2015)

16. Ogaldez, Theodore and Hilton, Adriel. Faculty Expectations of Administrative Leaders Behavior of the Department Chairs: The University Of Belize. Journal of Research Initiatives, 3 (1): 1 - 15. (2017)

17. Ragheb, Iman Zaghloul. Administrative development and evaluating the performance of directors of departments in pre-university education in the Arab Republic of Egypt, an unpublished $\mathrm{PhD}$ thesis, Ain Shams University. (2002)

18. Salah El-Din, Ahmed Diaa El-Din and Attia, Tariq Tohme. Academic leadership practices and their role in promoting a proactive approach to crisis management: A field study of a sample of university leaders in the faculties of the University of Anbar. Dinars Magazine. Iraq, (13): 289 - 321. (2018)

19. Samara, Nawaf Ahmed, Al-Adely and Abdel Salam Musa. Concepts and terminology in educational sciences. Dar Al-Maysara for publishing, distribution and printing. (2008)

20. Shahmandi, Elham; Silong, Abu Doud; Ismail, Ismi and Othman, Jamilah. Competencies, Roles and Effective Academic Leadership in World Class University. 